Purdue University

Purdue e-Pubs

CTRC Research Publications

Cooling Technologies Research Center

2012

\title{
The Importance of Turbulence during Condensation in a Horizontal Circular Minichannel
}

\section{E. da Riva}

Università degli Studi di Padova

Davide Del Col

Università degli Studi di Padova

S V. Garimella

Purdue University, sureshg@purdue.edu

Alberto Cavallini

Università degli Studi di Padova

Follow this and additional works at: https://docs.lib.purdue.edu/coolingpubs

da Riva, E.; Del Col, Davide; Garimella, S V.; and Cavallini, Alberto, "The Importance of Turbulence during Condensation in a Horizontal Circular Minichannel" (2012). CTRC Research Publications. Paper 172.

http://dx.doi.org/http://dx.doi.org/10.1016/j.ijheatmasstransfer.2012.02.026

This document has been made available through Purdue e-Pubs, a service of the Purdue University Libraries. Please contact epubs@purdue.edu for additional information. 


\title{
THE IMPORTANCE OF TURBULENCE DURING CONDENSATION IN A HORIZONTAL CIRCULAR MINICHANNEL
}

\author{
Enrico Da Riva $^{\mathrm{a} 1}$, Davide Del Col ${ }^{\mathrm{a}}$, Suresh V. Garimella ${ }^{\mathrm{b}}$ and Alberto Cavallini ${ }^{\mathrm{a}}$ \\ ${ }^{a}$ Dipartimento di Fisica Tecnica, Università degli Studi di Padova \\ Via Venezia 1, I-35131 Padova, Italy \\ ${ }^{\mathrm{b}}$ Cooling Technologies Research Center, School of Mechanical Engineering \\ Purdue University, 585 Purdue Mall, West Lafayette, IN 47907-2088, USA \\ *Corresponding author \\ email: davide.delcol@unipd.it, Telephone: 00390498276891 , Fax: 00390498276896
}

\begin{abstract}
Three-dimensional simulations of condensation of refrigerant R134a in a horizontal minichannel are presented. Mass fluxes ranging from $50 \mathrm{~kg} \mathrm{~m}^{-2} \mathrm{~s}^{-1}$ up to $1000 \mathrm{~kg} \mathrm{~m}^{-2} \mathrm{~s}^{-1}$ are considered in a circular minichannel of $1 \mathrm{~mm}$ diameter, and uniform wall and vapour-liquid interface temperatures are imposed as boundary conditions. The Volume of Fluid (VOF) method is used to track the vapour-liquid interface; the effects of interfacial shear stress, gravity and surface tension are taken into account. The influence of turbulence in the condensate film is analysed and compared against the assumption of laminar condensate flow by employing different computational approaches and validating the results against experimental data. Under the assumption of laminar condensate flow, experimental heat transfer coefficient data at low mass fluxes can be predicted, but the computed heat transfer coefficient is found to be almost independent of mass flux and vapour quality. Only when turbulence in the condensate film is taken into account does the numerical model capture the influence of mass flux that is observed in the experimental measurements.
\end{abstract}

\section{Keywords}

Minichannel, Condensation, VOF, Turbulence, Modeling

\section{Nomenclature}

A cross-sectional area, $\pi D^{2} / 4$

$\left[\mathrm{m}^{2}\right]$

$c_{p} \quad$ isobaric specific heat

$\left[\mathrm{J} \mathrm{kg}^{-1} \mathrm{~K}^{-1}\right]$

$D \quad$ internal diameter

[m] 


\begin{tabular}{|c|c|c|}
\hline$e_{p}$ & percentage deviation, $e_{p}=100^{*}\left(H T C_{C A L C}-H T C_{E X P}\right) / H T C_{E X P}$ & {$[\%]$} \\
\hline$e_{R}$ & average deviation, $e_{R}=\left(1 / N_{p}\right) \Sigma e_{p}$ & {$[\%]$} \\
\hline$f_{1}$ & dumping function for low-Re correction & {$[-]$} \\
\hline$g$ & acceleration due to gravity & {$\left[\mathrm{kg} \mathrm{m} \mathrm{s}^{-2}\right]$} \\
\hline$G$ & mass flux, $m / \mathrm{A}$ & {$\left[\mathrm{kg} \mathrm{m}^{-2} \mathrm{~s}^{-1}\right]$} \\
\hline$h$ & specific sensible enthalpy & {$\left[\mathrm{J} \mathrm{kg}^{-1}\right]$} \\
\hline$h_{L V}$ & latent heat of vaporization & {$\left[\mathrm{J} \mathrm{kg}^{-1}\right]$} \\
\hline HTC & cross-sectional average heat transfer coefficient & {$\left[\mathrm{W} \mathrm{m}{ }^{-2} \mathrm{~K}^{-1}\right]$} \\
\hline$k$ & turbulent kinetic energy & {$\left[\mathrm{m}^{2} \mathrm{~s}^{-2}\right]$} \\
\hline$m$ & mass flow rate & {$\left[\mathrm{kg} \mathrm{s}^{-1}\right]$} \\
\hline$N_{p}$ & number of data points & {$[-]$} \\
\hline$p$ & pressure & {$[\mathrm{Pa}]$} \\
\hline $\mathrm{Pe}_{\mathrm{t}}$ & turbulent Peclet number, $\operatorname{Pe}_{\mathrm{t}}=\operatorname{Pr} \mu_{t} / \mu$ & {$[-]$} \\
\hline $\operatorname{Pr}$ & molecular Prandtl number, $\operatorname{Pr}=c_{p} \mu / \lambda$ & {$[-]$} \\
\hline $\operatorname{Pr}_{t}$ & turbulent Prandtl number, $\operatorname{Pr}_{t}=0.85$ & {$[-]$} \\
\hline $\mathrm{r}$ & coefficient in eqs. (12) and (13) & {$\left[\mathrm{s}^{-1}\right]$} \\
\hline $\operatorname{Re}_{\mathrm{GO}}$ & all-vapour Reynolds number, $G D / \mu_{G}$ & {$[-]$} \\
\hline $\mathrm{Re}_{\mathrm{L}}$ & liquid Reynolds number, $G D(1-x) / \mu_{L}$ & {$[-]$} \\
\hline $\operatorname{Re}_{\mathrm{LO}}$ & all-liquid Reynolds number, $G D / \mu_{L}$ & {$[-]$} \\
\hline$S$ & mass source due to phase change & {$\left[\mathrm{kg} \mathrm{m}^{-3} \mathrm{~s}^{-1}\right]$} \\
\hline$T$ & temperature & {$[\mathrm{K}]$} \\
\hline$u$ & velocity & {$\left[\mathrm{m} \mathrm{s}^{-1}\right]$} \\
\hline$u_{\tau}$ & friction velocity, $\left(\tau_{w} / \rho\right)^{1 / 2}$ & {$\left[\mathrm{~m} \mathrm{~s}^{-1}\right]$} \\
\hline$x$ & vapour quality, $m_{G} / m$ & {$[-]$} \\
\hline
\end{tabular}

\section{Greek letters}

$\alpha \quad$ volume fraction $\quad[-]$

$\delta \quad$ condensate liquid thickness $\quad[\mathrm{m}]$

$\delta^{+} \quad$ dimensionless, sublayer-scaled distance, $\delta u_{\tau} \rho / \mu$

$\theta \quad$ angular coordinate from channel top $\quad\left[{ }^{\circ}\right]$

$\kappa \quad$ interface curvature $\left[\mathrm{m}^{-1}\right]$

$\lambda$ molecular thermal conductivity $\quad\left[\mathrm{W} \mathrm{m}^{-1} \mathrm{~K}^{-1}\right]$

$\mu \quad$ molecular dynamic viscosity $\quad[\mathrm{Pa} \mathrm{s}]$

$\mu_{t} \quad$ turbulent viscosity [Pa s]

$\rho$ density $\left[\mathrm{kg} \mathrm{m}^{-3}\right]$

$\sigma \quad$ surface tension $\quad\left[\mathrm{N} \mathrm{m}^{-1}\right]$

\footnotetext{
${ }^{1}$ Present address: CERN - European Organization for Nuclear Research, CFD Team, CH-1211 Geneva 23, Switzerland
} 

$\sigma_{N} \quad$ standard deviation, $\sigma_{N}=\left\{\left[\Sigma\left(e_{p}-e_{R}\right)^{2}\right] /\left(N_{p}-1\right)\right\}^{0.5}$
$\tau_{w} \quad$ wall shear stress
$\omega \quad$ specific dissipation rate of turbulent kinetic energy
$\left[\mathrm{s}^{-1}\right]$

\section{Subscripts}

$\begin{array}{ll}\text { CALC } & \text { calculated } \\ \text { eff } & \text { effective } \\ \text { EXP } & \text { experimental } \\ \text { G } & \text { gas/vapour phase } \\ \text { L } & \text { liquid phase } \\ \text { S } & \text { saturation } \\ \mathrm{t} & \text { turbulent }\end{array}$

\section{INTRODUCTION}

Because of the increasing demand for higher performance in compact devices, minichannel heat exchangers have been widely studied. This kind of heat exchanger is used in electronics cooling, automotive air-conditioning and other applications. In the case of condensers for automotive airconditioning applications, for example, extruded aluminum multi-port minichannel tubing is a technology that has found widespread use. Minichannel technology is also promising for refrigerant charge reduction in heating and cooling applications, especially for safety reasons when using "natural refrigerants" such as ammonia or hydrocarbons [1,2,3], and for reducing greenhouse gas emission when using conventional halogenated refrigerants.

The condensation mechanisms in minichannels were treated by Garimella [4], while a review of condensation in minichannels covering flow regimes, pressure drop and heat transfer modeling was compiled by Cavallini et al. [5]. Local heat transfer coefficients for refrigerants R134a and R32 obtained from the measurement of local heat flux and saturation and wall temperatures within a single horizontal circular $0.96 \mathrm{~mm}$ i.d. minichannel at mass fluxes in the range $100 \mathrm{~kg}$ $\mathrm{m}^{-2} \mathrm{~s}^{-1}<G<1200 \mathrm{~kg} \mathrm{~m}^{-2} \mathrm{~s}^{-1}$ were reported by Matkovic et al. [6] and Cavallini et al. [7]. Heat transfer coefficients during condensation of R134a over the mass flux range $150 \mathrm{~kg} \mathrm{~m}^{-2} \mathrm{~s}^{-1}<G$ $<750 \mathrm{~kg} \mathrm{~m}^{-2} \mathrm{~s}^{-1}$ were measured for three horizontal circular multiport minichannels $(0.5 \mathrm{~mm}<$ $D<1.5 \mathrm{~mm}$ ) by Bandhauer at al. [8]. Local condensation heat transfer coefficients with R134a for mass fluxes of $100 \mathrm{~kg} \mathrm{~m}^{-2} \mathrm{~s}^{-1}<G<700 \mathrm{~kg} \mathrm{~m}^{-2} \mathrm{~s}^{-1}$ in two rectangular horizontal multiport tubes of $1.1 \mathrm{~mm}$ and $0.8 \mathrm{~mm}$ hydraulic diameter were reported by Koyama et al. [9].

However, the extent to which condensation inside minichannels differs from macroscale condensation is still not fully understood. As an example, the measurements by Matkovic et al. 
[6], except for the lowest mass flux $\left(G=100 \mathrm{~kg} \mathrm{~m}^{-2} \mathrm{~s}^{-1}\right)$, do not show significant differences from the trends expected for macroscale tubes: all experimental data at mass fluxes higher than $100 \mathrm{~kg} \mathrm{~m}^{-2} \mathrm{~s}^{-1}$ could be predicted within $15 \%$ by the Cavallini et al. [10] empirical correlation, which was developed from a database for macroscale tubes $(3 \mathrm{~mm}<D<8 \mathrm{~mm})$. Even if selected empirical correlations can predict specific experimental results with reasonable accuracy (see $[4,5]$ ), an established predictive model is unavailable, and a more complete understanding of the two-phase flow and heat transfer process in minichannels is needed for the design and optimization of heat exchangers. In particular, it is crucial to understand the relative importance of the three main forces acting upon the condensate film, viz. the interfacial shear stress due to vapor flow, the gravitational force, and the surface tension. Theoretical models can be useful in determining the influence of mass flux, channel dimension, and channel geometry on these forces.

Wang and Rose [11] reported a detailed theoretical study of film condensation in square and triangular minichannels over the mass flux range $100 \mathrm{~kg} \mathrm{~m}^{-2} \mathrm{~s}^{-1}<G<1300 \mathrm{~kg} \mathrm{~m}^{-2} \mathrm{~s}^{-1}$, covering different channel sizes in the range of 0.5-5 mm, and refrigerants R134a, R22 and R410A. An analogous study for circular minichannels was conducted by Wang and Rose [12]. In their work, laminar flow is assumed in the condensate film and inertia and convection terms are neglected. The interfacial shear stress due to vapour flow is computed by means of the Churchill empirical correlation [13] using the approach suggested by Mickley et al. [14]. According to Wang and Rose [11], surface tension is expected to be the dominating mechanism as compared to interfacial shear stress for square and triangular channels of $1 \mathrm{~mm}$ side dimension, since the computed average cross-sectional heat transfer coefficient is almost the same for all mass fluxes over a large portion of the channel length. At the same hydraulic diameter and operating conditions, the heat transfer coefficients computed for a circular minichannel were reported to be approximately half as large as for the triangular and square channels [12].

A theoretical and numerical model to predict laminar annular film condensation heat transfer in mini and microchannels was recently developed by Nebuloni and Thome [15]. Some of the original simplifying assumptions made by Wang and Rose [11] (constant wall temperature, negligible axial interfacial curvature, negligible non-linear terms in the momentum equation, and vapour to liquid relative velocity approximated as the vapour velocity) were relaxed. Besides, interphase mass transfer and near-wall effects (disjoining pressure) were also considered in order to allow the model to be scaled down to very small diameters (i.e., $D=10$ $\mu \mathrm{m})$. This model [15] is reported to display the same qualitative trends (dependency on wall subcooling, mass flux, channel size and fluid properties) as compared to [11]; besides, it was shown to predict within 20\% measurements by Yan and Lin [16] of condensation of R134a in circular channels with diameter $0.5 \mathrm{~mm}<D<2 \mathrm{~mm}$. 
Panday [17] developed a two-dimensional numerical methodology to determine the heat transfer coefficients, film thickness and pressure drop for film condensation inside a vertical tube and between parallel plates. The analysis does not neglect inertia and convection terms in the governing equations, and, unlike the models by Wang and Rose [11] and Nebuloni and Thome [15], turbulence in the vapour and condensate film is taken into account using mixing length turbulence models. For flows at high velocities, turbulence in the liquid and vapour phases was shown to increase heat transfer coefficient.

In the present work, steady-state CFD simulations of condensation of R134a in a minichannel using the Volume of Fluid (VOF) method are presented. This method can handle multiphase flows of immiscible fluids, tracking the motion of the interface between them without using empirical closure laws to model the interaction between the phases. Mass fluxes $G$ ranging from $100 \mathrm{~kg} \mathrm{~m}^{-2} \mathrm{~s}^{-1}$ to $G=1000 \mathrm{~kg} \mathrm{~m}^{-2} \mathrm{~s}^{-1}$ are considered in a circular minichannel of $1 \mathrm{~mm}$ inner diameter; all the pertinent effects (shear, gravity and surface tension) are taken into account. As compared to past theoretical work in the literature, a full three-dimensional analysis of both the liquid and vapour phases is undertaken. A low-Re turbulence model is used for both phases. Indeed, the assumption of laminar film flow adopted in [11] and [15] is not always valid at the mass fluxes typically encountered in minichannel condensers. In the present work, two different computational approaches are considered: the first approach (referred to as "laminar liquid film") corresponds to the assumption that the flow is laminar in the liquid phase and turbulent in the vapour phase; in the second approach (referred to as "SST $k$ - $\omega$ approach"), instead, the same turbulence model is applied through the whole computational domain.

Theoretical models in the literature have also not been widely validated against experiments, and some of the predictions for minichannels showed trends that are contrary to those from experiments. As an example, the local heat transfer coefficients predicted by Wang and Rose [11] at $100 \mathrm{~kg} \mathrm{~m}^{-2} \mathrm{~s}^{-1}<G<1300 \mathrm{~kg} \mathrm{~m}^{-2} \mathrm{~s}^{-1}$ do not depend on mass flux for a large portion of the channel length; several experimental data sets for both circular and non-circular minichannels, however, show a strong dependence on mass flux $[6,8,9,18,19]$. All reported numerical results in the present work are compared to the experimental data of Matkovic et al. [6].

\section{NUMERICAL SIMULATIONS}

Three-dimensional steady-state simulations of condensation of R134a in a $1 \mathrm{~mm}$ i.d. circular minichannel are performed at different mass fluxes $\left(G=50 \mathrm{~kg} \mathrm{~m}^{-2} \mathrm{~s}^{-1}\right.$ to $\left.1000 \mathrm{~kg} \mathrm{~m}^{-2} \mathrm{~s}^{-1}\right)$. Details of the channel length, outlet vapour quality and all-liquid and all-vapour Reynolds numbers are reported in Table 1 for each case considered. Both phases are assumed as incompressible, the inlet thermodynamic vapour quality is $x=1$, and the channel is horizontally oriented. The minichannel wall is assumed to be smooth and held isothermal at a uniform temperature $30^{\circ} \mathrm{C}$, 
while the vapour-liquid temperature is set to be uniform and equal to the fluid saturation temperature $40^{\circ} \mathrm{C}$. The saturation temperature drop due to the pressure drop is neglected in the simulations and a pressure boundary condition is imposed at the outlet.

Longitudinal wall heat conduction may play a role in heat exchangers and test sections which experience either a large longitudinal temperature gradient or a highly non-uniform distribution of the heat transfer coefficient [20]; since neither condition is encountered during condensation under the present boundary conditions, the effect of longitudinal conduction is neglected.

It is noted that steady-state simulations do not allow for wavy flow or intermittent flows such as plug/slug flows to be predicted. According to Garimella [4], as the hydraulic diameter decreases (particularly for $D<3 \mathrm{~mm}$ ), the range of the annular flow regime increases and the wavy regime decreases in importance and almost disappears at $D=1 \mathrm{~mm}$, while the region of the intermittent regime widens, reflecting a diminishing influence of the gravity force. The flow pattern map of Colemann and Garimella [21] and Garimella [4], developed from experimental visualizations of $\mathrm{R} 134 \mathrm{a}$ at $52^{\circ} \mathrm{C}$ in a $1 \mathrm{~mm}$ i.d. circular pipe, is shown in Fig. 1. Garimella et al. [22] proposed diameter-dependent equations for the transition between intermittent and non-intermittent flow, obtained for R134a in circular minitubes; the transition curve for a $1 \mathrm{~mm}$ diameter channel is included in Fig. 1. The map shows that neither a wavy nor an intermittent regime is expected under the conditions of the present work, provided that the outlet vapor quality is above 0.4. It is noticed, however, that the transition criterion was developed from experimental data at mass fluxes of $150 \mathrm{~kg} \mathrm{~m}^{-2} \mathrm{~s}^{-1}<\mathrm{G}<750 \mathrm{~kg} \mathrm{~m}^{-2} \mathrm{~s}^{-1}$, and does not cover the whole mass flux range considered in the simulations $\left(50 \mathrm{~kg} \mathrm{~m}^{-2} \mathrm{~s}^{-1}<\mathrm{G}<1000 \mathrm{~kg} \mathrm{~m}^{-2} \mathrm{~s}^{-1}\right)$. Besides, as can be seen in Fig. 1, mist flow is expected to occur at $G>400 \mathrm{~kg} \mathrm{~m}^{-2} \mathrm{~s}^{-1}$ and high vapour quality. Because of the steady-state solution approach, the entrainment of droplets into the vapour core cannot be solved in the present numerical simulations; therefore, the flow is assumed to be annular even in the mist flow region of the flow map. The validity of the numerical results under this assumption is, however, verified by means of comparison against experimental data.

Selected single-phase simulations are performed in order to obtain the fully developed turbulent solution for the vapour flow. The results of these simulations are then used to set the inlet boundary conditions for the z-velocity, the turbulent kinetic energy and the turbulent specific dissipation rate.

The domain is discretized into approximately $1,150,000$ hexahedral cells. In order to fully resolve the viscous sublayer in the liquid film region and maintain the dimensionless distance from the wall of the first cell lower than $\delta^{+}=1$, the radial thickness of the cells in the near-wall region is $1 \mu \mathrm{m}$, while the mesh is much coarser in the core region $(\approx 20 \mu \mathrm{m})$. The angular discretization is $3.5^{\circ}$, with 360 nodes along the $z$ axis; the mesh length is scaled for each test case as shown in Table 1 , in order to achieve a vapour quality of approximately 0.5 at the channel outlet. Two mesh-independence tests are performed: the cases at $G=100 \mathrm{~kg} \mathrm{~m}^{-2} \mathrm{~s}^{-1}$ 
(laminar film approach) and $G=800 \mathrm{~kg} \mathrm{~m}^{-2} \mathrm{~s}^{-1}$ (SST $k$ - $\omega$ approach) were run at approximately twice as fine a mesh size $(2,200,000$ cells); the difference in terms of computed global heat transfer rate at the wall was below $0.3 \%$ in both cases.

\subsection{VOF Method}

The VOF method [23] is capable of computing multiphase flows of immiscible fluids while tracking the motion of the interface between the fluids without necessitating empirical closure laws to model the interaction between the phases. As compared to the simulation of singlephase flows, an additional equation is needed for the volume fraction $\alpha$, which represents the portion of the volume of the computational cell filled with each additional phase beyond the primary. Volume fractions of all phases sum to unity. Fluid properties are computed within each control volume based on the volume fraction of each phase, using an appropriate mixture rule. The governing continuity, momentum, turbulence and energy equations are then solved for a single set of shared flow variables (velocity, pressure, etc.). The numerical procedure adopted in the present work is implemented in the commercial package FLUENT [24]. The modified High Resolution Interface Capturing (HRIC) scheme [25] is used in the present steady-state simulations together with the implicit scheme for time discretization.

Density $\rho$, molecular viscosity $\mu$ and thermal conductivity $\lambda$ are locally computed for each cell by means of an arithmetic mean:

$$
\varphi=\varphi_{L} \alpha_{L}+\varphi_{G} \alpha_{G} \quad \text { with } \varphi=\rho, \lambda, \mu
$$

Some implementations of the VOF method adopt a harmonic mean for the computation of viscosity. According to Boeck et al. [26], the arithmetic mean is optimal when the interface is perpendicular to the flow, while the harmonic mean is recommended when the interface is parallel.

Since the wall temperature is $10 \mathrm{~K}$ lower than the saturated fluid temperature, the liquid viscosity and thermal conductivity increase by approximately $14 \%$ and $6 \%$, respectively, at the wall as compared to their values at the interface. For this reason, all properties are considered to be temperature-dependent and are locally computed for each computational cell from the REFPROP database [27].

The following continuity equations are solved:

$$
\nabla \cdot\left(\stackrel{\rho}{u} \alpha_{L}\right)=\frac{S}{\rho_{L}}
$$




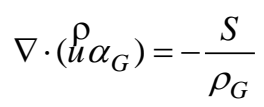

where $S$ is the mass source term due to phase change.

The usual Navier-Stokes equations are solved for momentum in the cells where only one of the two phases is present. At the interface $\left(0<\alpha_{L}<1\right)$, the force due to the surface tension $F_{\sigma}$ must be taken into account as:

$$
\nabla \cdot(\rho \mu u)=-\nabla p+\nabla \cdot\left[\left(\mu+\mu_{t}\right)\left(\nabla u+\nabla u^{\rho}\right)\right]+\rho g+\mu_{\sigma}
$$

The effect of surface tension is computed by means of the CSF (Continuum Surface Force) model of Brackbill et al. [28]. The vapour-liquid interface is treated as a transition region of finite thickness and the effect of surface tension is modelled as a volume force. The surface normal is computed as the gradient of the volume fraction scalar; then, the interface curvature $\kappa$ is obtained as follows:

$$
\kappa=\nabla \cdot \frac{\nabla \alpha_{L}}{\left|\nabla \alpha_{L}\right|}
$$

The volumetric force due to surface tension is finally computed as follows:

$$
\rho_{\sigma}=\sigma \frac{\rho}{0.5\left(\rho_{L}+\rho_{G}\right)} \kappa \nabla \alpha_{L}
$$

All scalar values are shared by the phases throughout the domain, and thus no particular special treatment is needed for the energy or turbulence equations.

The following energy equation is solved:

$$
\nabla \cdot(u \rho h)=\nabla \cdot\left(\lambda_{\text {eff }} \nabla T\right)+h_{L V} S
$$

where $\lambda_{\text {eff }}$ is the effective thermal conductivity, $h$ is the specific sensible enthalpy and the last term (i.e. $h_{L V} S$ ) is the energy source due to phase change. The effective thermal conductivity is computed as follows:

$$
\lambda_{\text {eff }}=\lambda+\frac{c_{p} \mu_{t}}{\operatorname{Pr}_{t}}
$$


For turbulent condensate film flow, the turbulent conductivity $c_{P} \mu_{t} \operatorname{Pr}_{t}^{-1}$ is the dominant term in Eq. (8); therefore the estimation of the turbulent viscosity $\mu_{t}$ is crucial for the computation of heat transfer. The turbulent Prandtl number is set to $\operatorname{Pr}_{t}=0.85$ in the present simulations.

The specific sensible enthalpy, as well as the isobaric specific heat, are computed as a weighted average as follows:

$$
\begin{aligned}
& \varphi=\frac{\alpha_{L} \rho_{L} \varphi_{L}+\alpha_{G} \rho_{G} \varphi_{G}}{\alpha_{L} \rho_{L}+\alpha_{G} \rho_{G}} \quad \text { with } \varphi=h, c_{P} \\
& h(T)=\int_{T_{S}}^{T} c_{p} d T
\end{aligned}
$$

\subsection{Refrigerant mass flux and turbulence modeling}

The choice of the refrigerant mass flux is a key factor in the design of minichannel condensers. On the one hand, by increasing the mass flux the condensation heat transfer coefficient is increased; on the other hand, the pressure drop and the saturation temperature drop also increase. An analysis of the optimal mass flux during intube condensation is reported in [29]. However, the present simulations cover the whole range of usual operating mass fluxes. Empirical heat transfer correlations suggest that the effect of turbulence on the liquid film during condensation starts at $\operatorname{Re}_{\mathrm{L}}=\operatorname{Re}_{\mathrm{LO}}(1-x) \approx 1000[30,31]$, as compared to the typical singlephase value of 2300; Carpenter and Colburn [32] suggested that the condensate layer in annular flow may become turbulent at even lower liquid Reynolds numbers $\left(\operatorname{Re}_{\mathrm{L}}=240\right)$.

Mass fluxes ranging from $G=50 \mathrm{~kg} \mathrm{~m}^{-2} \mathrm{~s}^{-1}$ to $1000 \mathrm{~kg} \mathrm{~m}^{-2} \mathrm{~s}^{-1}$ are considered in the present simulations: according to the all-vapour and all-liquid Reynolds numbers reported in Table 1, the vapour flow can be considered turbulent for all the test cases, while no a priori assumption can be made for the liquid flow. Depending on the mass flux and the position along the minichannel, both turbulent and laminar flow may occur in the condensate film during the actual operation of R134a in $1 \mathrm{~mm}$ diameter minichannel condensers. This is an important observation, since existing theoretical models for minichannel condensation $[11,15]$ rely on the assumption of laminar flow.

In order to properly resolve the near-wall region in the condensate film, low-Reynolds number forms of the $k$ - $\omega$ turbulence models (which allow for the viscous sublayer and the laminarturbulent transition to be resolved) are selected. Available turbulence models for CFD computations, however, are semi-empirical and have been developed for single-phase flows; therefore their applicability across a gas-liquid interface has not been established. For purposes of evaluation, two different modeling approaches are considered and compared to each other 
and to experimental data: as stated in the Introduction, in the "laminar liquid film" approach, laminar flow is imposed in the liquid phase, while in the "SST $k-\omega$ approach", a turbulence model is used throughout the computational domain.

\section{Laminar liquid film approach}

The laminar liquid film approach is based on the low-Re form of the Wilcox $k$ - $\omega$ model $[24,33]$ and details are provided in Da Riva and Del Col [34]. The formulation of the turbulent viscosity is modified as follows:

$\mu_{t}=f_{1} \frac{\rho_{G} k}{\omega} \alpha_{G}$

where $f_{l}$ is a dumping function for low-Re correction [33].

As compared to the usual formulation, the vapour phase volume fraction $\alpha_{G}$ is added: in the vapour phase the turbulent viscosity $\mu_{t}$ given by Eq. (11) is equal to the value given by the standard low-Re $k$ - $\omega$ model, while in the liquid phase the turbulent viscosity $\mu_{t}$ is set equal to zero and laminar flow is imposed. Since in Wilcox's $k-\omega$ model [33] the turbulence production is proportional to the turbulent viscosity, the turbulence production is also suppressed in the liquid phase. At the interface, the turbulent viscosity is blended between zero and the value given in the vapour phase.

This turbulence modeling approach is expected to perform better for the simulation test cases in Table 1 at the lowest mass flux, displaying turbulent vapour flow and laminar liquid flow. The adoption of this approach avoids the uncertainty arising from the use of a turbulence model across the gas-liquid interface, since turbulence is considered only on the vapour side.

\section{SST $k$ - $\omega$ approach}

In the SST $k-\omega$ approach, the low-Reynolds number form of the Shear Stress Transport (SST) $k$ $\omega$ model by Menter [35] is used throughout the computational domain without any modification. As compared to the standard $k$ - $\omega$ model of Wilcox [33], this model includes two major modifications:

- The model ensures a gradual change from the standard $k-\omega$ model in the inner region of the boundary layer to a high-Reynolds number version of the $k-\varepsilon$ model in the outer part of the boundary layer.

- The formulation of the turbulent viscosity is modified to introduce a stress limiter formulation based on the Bradshaw [36] assumption (i.e., the Reynolds shear stress in a boundary layer is proportional to the turbulent kinetic energy). 
The second of these modifications is very important for the present work. The turbulent viscosity in the boundary layer is computed using both the standard $k-\omega$ model formulation [33] and the formulation based on the Reynolds shear stress form proposed by Bradshaw; then the minimum of the two values is chosen. In this way, in the boundary layers where the production of turbulent kinetic energy exceeds its dissipation (as is expected to happen in the highly strained condensate film flow during condensation at high mass flux), the magnitude of the Reynolds shear stress is limited as compared to the standard $k-\omega$ model. This point will be discussed further in Section 3.5.

A similar stress-limiter was introduced by Wilcox [37] in a recent revised formulation of the $k$ $\omega$ model. Besides, when using the standard $k$ - $\omega$ model [33] together with the VOF method, the adoption of an empirical turbulence damping modification [38] is suggested in order to reduce turbulence when a high velocity gradient exists at the interface between two fluids [24].

\subsection{Phase change modeling}

The numerical technique described by the following equations by Lee [39] is used in modeling the phase change process:

$$
\begin{array}{ll}
S=-r \alpha_{L} \rho_{L} \frac{T-T_{S}}{T_{S}} & T \geq T_{S} \\
S=r \alpha_{G} \rho_{G} \frac{T_{S}-T}{T_{S}} & T<T_{S}
\end{array}
$$

where $S$ is the source term in the continuity equations (2) and (3) and in the energy equation (7), $T$ is the cell temperature and $r$ is a positive numerical coefficient.

In the condensation of a pure halogenated fluid at common working pressure, the interfacial temperature can be assumed to be equal to the saturation temperature [40]: equations (12) and (13) above offer a simple numerical technique for implementation of such an assumption as a boundary condition. If at a certain computational step the temperature of a cell in the domain is higher than the saturation temperature, the first of the two equations is used: if this cell belongs to the vapour phase $\left(\alpha_{L}=0\right)$ no mass transfer is computed; if this cell belongs to the liquid phase $\left(\alpha_{L}>0\right)$ instead, mass transfer from the liquid to the vapour phase is computed. Besides, the temperature of the cell is decreased by the source term $h_{L V} S$ in Eq. (7). The computation is analogous for the cells with temperature lower than saturation. In this way, the presence of cells in the vapour phase with temperature lower than the saturation temperature is avoided, as is the presence of cells in the liquid phase with temperature higher than saturation. The source term $S$ is arbitrary fixed; however, mass, momentum and energy are conserved at every computational step. At convergence, the interface reaches the saturation temperature, while cells in the liquid and vapour phases reach a lower and higher temperature, respectively. 
In practice, the interfacial temperature obtained at convergence will not be exactly the saturation temperature. The optimal values for the coefficient $r$ strongly depend on the particular problem being solved and suitable values should be found for each case. Excessively small values of $r$ lead to a significant deviation between interfacial and saturation temperature. On the other hand, when higher values of the coefficient $r$ are used, the interface (i.e., the region of cells with $0<$ $\left.\alpha_{L}<1\right)$ is sharper and thinner, but values of $r$ that are too large cause numerical convergence problems. An example of the influence of the numerical value of $r$ on the computed temperature profile is available in Da Riva and Del Col [34]. In the present work, coefficients ranging from $r$ $=7.5 \times 10^{5} \mathrm{~s}^{-1}$ to $r=5 \times 10^{6} \mathrm{~s}^{-1}$ are used and the area-averaged interfacial temperature of the simulations is kept within around $1 \mathrm{~K}$ of the chosen saturation temperature.

\section{RESULTS AND DISCUSSION}

\subsection{Validation against experimental data}

The cross-sectional average heat transfer coefficient computed under the laminar liquid film assumption is plotted versus vapour quality in Fig. 2 together with the experimental measurements of Matkovic et al. [6] obtained in a $0.96 \mathrm{~mm}$ i.d. circular minichannel at the same saturation temperature as considered in the present simulation. A similar comparison is provided for the SST $k$ - $\omega$ approach in Fig. 3. The average percentage deviation $e_{p}$ and the standard deviation $\sigma_{N}$ between the computed and experimental data is reported in Table 2: Comparison between experimental and calculated cross sectional average heat transfers coefficients..

In the experimental apparatus used by Matkovic et al. [6], refrigerant R134a is cooled with water which does not ensure that the saturation-to-wall temperature difference is constant along the test section. The saturation-to-wall temperature difference ranges between $6.1 \mathrm{~K}$ and $13.1 \mathrm{~K}$ for the experimental data reported in Fig. 2 and Fig. 2, while in the simulations this difference is $10 \mathrm{~K}$ all along the computational domain. According to Cavallini et al. [10], some increment in the heat transfer coefficient is expected during stratified flow condensation as the saturationto-wall temperature difference falls; the same qualitative trend is predicted by the theoretical models of Wang and Rose [11] and Nebuloni and Thome [15]. This dependence, however, is not expected when the mass flux is high enough and stratification does not occur: indeed, the experimental heat transfer coefficients of Matkovic et al. [6] for R134a at $G=417 \mathrm{~kg} \mathrm{~m}^{-2} \mathrm{~s}^{-1}$ and for R32 at $G=200 \mathrm{~kg} \mathrm{~m}^{-2} \mathrm{~s}^{-1}$ display no effect of the saturation-to-wall temperature difference.

As can be seen in Fig. 2, the laminar liquid film approach displays a weak influence of the mass flux on the heat transfer coefficient only at high vapour qualities, while for vapour qualities less than $x=0.8$, the four series overlap. Such behavior is not consistent with the experimental data; however, reasonable agreement between the computed and measured values is obtained at mass fluxes lower than $G=200 \mathrm{~kg} \mathrm{~m}^{-2} \mathrm{~s}^{-1}$; it is important to note that at such low mass fluxes the 
assumption of laminar condensate film flow is expected to hold, since the maximum liquid Reynolds number is $\operatorname{Re}_{\mathrm{L}}=620$. On the contrary, the SST $k-\omega$ approach simulations are shown in Fig. 2 to display a dependence of the heat transfer coefficient on the mass flux consistent with experimental data. The experimental data at $G=200 \mathrm{~kg} \mathrm{~m}^{-2} \mathrm{~s}^{-1}$ and $G=100 \mathrm{~kg} \mathrm{~m}^{-2} \mathrm{~s}^{-1}$ are overpredicted; however, as the mass flux increases from $G=400 \mathrm{~kg} \mathrm{~m}^{-2} \mathrm{~s}^{-1}$ up to $G=1000 \mathrm{~kg} \mathrm{~m}^{-}$ ${ }^{2} \mathrm{~S}^{-1}$ the average deviation decreases and excellent agreement with experimental data is obtained at $G=800 \mathrm{~kg} \mathrm{~m}^{-2} \mathrm{~s}^{-1}$ and $G=1000 \mathrm{~kg} \mathrm{~m}^{-2} \mathrm{~s}^{-1}$.

According to the validation results reported in Table 2: Comparison between experimental and calculated cross sectional average heat transfers coefficients., the present numerical simulations match the experiments better with the laminar liquid film approach at mass fluxes of $G=200 \mathrm{~kg}$ $\mathrm{m}^{-2} \mathrm{~s}^{-1}$ and lower, and with the SST $k$ - $\omega$ approach at mass fluxes of $G=400 \mathrm{~kg} \mathrm{~m}^{-2} \mathrm{~s}^{-1}$ and higher. Considering these ranges, the global average percentage deviation between experimental and computed data is $e_{p}=4 \%$ and the standard deviation $\sigma_{N}=14 \%$.

Calculated heat transfer coefficients are plotted with respect to axial position at different mass fluxes in Fig. 4; all the series end at $x=0.5$ for consistency of comparison. By increasing the mass flux from $G=100 \mathrm{~kg} \mathrm{~m}^{-2} \mathrm{~s}^{-1}$ to $200 \mathrm{~kg} \mathrm{~m}^{-2} \mathrm{~s}^{-1}$, the channel length required to condense the fluid is almost doubled; however, by further increasing the mass flux to $G=400 \mathrm{~kg} \mathrm{~m}^{-2} \mathrm{~s}^{-1}$, the length is reduced as compared to $G=200 \mathrm{~kg} \mathrm{~m}^{-2} \mathrm{~s}^{-1}$. Thereafter increasing the mass flux up to $G$ $=1000 \mathrm{~kg} \mathrm{~m}^{-2} \mathrm{~s}^{-1}$ the length increase is lower than the global heat transfer rate increase since under turbulent flow conditions the mass flux displays a strong effect on the heat transfer coefficient. These considerations are important for the design of a condenser; however, it is noted that the saturation temperature drop due to the pressure drop is neglected in the simulations, so that the channel lengths reported in Fig. 4 are underpredicted, especially at high mass fluxes.

\subsection{Vapour-liquid interface}

The condensation heat flux is driven by the temperature difference between the interface, which is at the saturation temperature, and the tube wall, where the temperature is $10 \mathrm{~K}$ lower. The local heat transfer coefficient depends on the local thickness of the condensate film and the effective thermal conductivity along the thickness. The computed cross-sectional shapes of the interface at $G=100 \mathrm{~kg} \mathrm{~m}^{-2} \mathrm{~s}^{-1}$ up to and $G=1000 \mathrm{~kg} \mathrm{~m}^{-2} \mathrm{~s}^{-1}$ are shown in Fig. 5 .

Computational results for R134a condensation at $G=100 \mathrm{~kg} \mathrm{~m}^{-2} \mathrm{~s}^{-1}$ in a $1 \mathrm{~mm}$ minichannel obtained with the present numerical model under the assumption of a laminar condensate flow are discussed in detail in Da Riva and Del Col [34]. At the beginning of the condensation process, high heat transfer coefficients are achieved (see Fig. 2) since the condensate film is very thin all around the tube wall. Moving downstream, the film thickness increases until it reaches approximately $20 \mu \mathrm{m}$ and the condensate liquid drains by gravity: in the upper half of 
the channel, the film thickness stays almost constant while the film at the bottom of the minichannel becomes thicker. All the liquid condensed in the upper part of the tube is drained to the bottom by gravity instead of being carried in the axial direction by the shear stress due to the vapour flow. Because of the stratification of the liquid film, the average heat transfer coefficient in the upper half is more than three times higher than the value in the lower half at a vapour quality of 0.5. As seen in Fig. 5, numerical results at $G=200 \mathrm{~kg} \mathrm{~m}^{-2} \mathrm{~s}^{-1}$ display these same features. The influence of gravity on condensation inside minichannels is discussed in Da Riva and Del Col [41]: the stratification due to gravity at $G=100 \mathrm{~kg} \mathrm{~m}^{-2} \mathrm{~s}^{-1}$ is shown to enhance the heat transfer since the condensate thickness is held in check in the upper region of the channel. For this reason, the total channel length required to condense the refrigerant to a vapour quality of 0.5 is $66 \mathrm{~mm}$ in the horizontal minichannel and $90 \mathrm{~mm}$ in the vertical case. The effect of surface tension is also discussed in Da Riva and Del Col [41]: a minor influence $(\approx 2 \%$ in the global heat transfer rate) is seen only when condensate stratification occurs in the horizontal configuration at $G=100 \mathrm{~kg} \mathrm{~m}^{-2} \mathrm{~s}^{-1}$; in this case, because of the effect of surface tension, the minimum liquid film thickness (corresponding to the maximum heat flux) is achieved at roughly half the channel height and not at the top of the channel.

As the mass flux is increased, Fig. 5 shows that the vapour-liquid interface gradually transitions to an almost completely axisymmetrical cross-sectional shape. At the highest mass flux considered $\left(G=1000 \mathrm{~kg} \mathrm{~m}^{-2} \mathrm{~s}^{-1}\right)$, the distribution of the local heat transfer coefficient and the local thickness is axisymmetrical all along the computational domain. Two different flow patterns can be distinguished in Fig. 5 with regard to the condensate film thickness at the top of the channel. During stratified flow this thickness stays constant along the channel length, while in axisymmetrical flow this thickness increases with distance along the channel: at $G=100 \mathrm{~kg}$ $\mathrm{m}^{-2} \mathrm{~s}^{-1}$ and $G=200 \mathrm{~kg} \mathrm{~m}^{-2} \mathrm{~s}^{-1}$ this transition occurs very close to the channel inlet; at $G=400 \mathrm{~kg}$ $\mathrm{m}^{-2} \mathrm{~s}^{-1}$ and $G=600 \mathrm{~kg} \mathrm{~m}^{-2} \mathrm{~s}^{-1}$ it occurs at around $x=0.7$; at $G=800 \mathrm{~kg} \mathrm{~m}^{-2} \mathrm{~s}^{-1}$ it occurs at around $x=0.6$; finally at $G=1000 \mathrm{~kg} \mathrm{~m}^{-2} \mathrm{~s}^{-1}$ it does not occur within the vapour quality range considered in the simulation.

\subsection{Velocity field}

In the theoretical models of Wang and Rose [11] and Nebuloni and Thome [15] the vapour flow is treated as one-dimensional and the circumferential variations of interfacial shear stress are neglected. Besides, in both cases the shear stress is computed by means of the single-phase Churchill empirical correlation [13] using the approach suggested by Mickley et al. [14] to take into account the effect of mass transfer. The mean vapour velocity is used in the Churchill correlation by Wang and Rose [11], while the difference between the mean vapour and liquid velocities is used by Nebuloni and Thome [15]. In the present model, a full three-dimensional analysis by means of a turbulence model is performed for the vapour core so that both the axial 
and circumferential variations of the velocity field are taken into account. This is an important consideration because the local interfacial shear stress and the turbulent viscosity and effective thermal conductivity depend on the local strain rate.

Numerical results of the axial velocity profile along the vertical axis at different vapour qualities are shown in Fig. 6 for $G=100 \mathrm{~kg} \mathrm{~m}^{-2} \mathrm{~s}^{-1}$ and $G=1000 \mathrm{~kg} \mathrm{~m}^{-2} \mathrm{~s}^{-1}$; the diamond symbols in the graph represent the position of the vapour-liquid interface in each case. At $G=100 \mathrm{~kg} \mathrm{~m}^{-2} \mathrm{~s}^{-1} \mathrm{a}$ strong influence of stratification is seen and the velocity profile is linear across the entire condensate film since the flow is laminar. At $G=1000 \mathrm{~kg} \mathrm{~m}^{-2} \mathrm{~s}^{-1}$, in contrast, the velocity profile is almost completely axisymmetrical and a deviation from the linear profile due to the effect of turbulence is noted. As the vapour quality decreases, the interfacial velocity at the bottom increases in both cases, reaching a maximum at around $x=0.6$ beyond which the interfacial velocity decreases.

\subsection{Assumption of laminar condensate flow}

The cross-sectional average heat transfer coefficients computed with the present numerical model under the assumption of laminar condensate film flow are compared in Fig. 7 (a) against the predictions from the Wang and Rose [11,42] model at the same operating conditions. Very similar cross-sectional heat transfer coefficients are obtained with the two approaches; in addition, the local condensate film thickness and the local heat transfer coefficients in Wang and Rose [12] and Da Riva and Del Col [34,41] match very well. Predictions with the SST $k-\omega$ approach at $G=50 \mathrm{~kg} \mathrm{~m}^{-2} \mathrm{~s}^{-1}$ are also included in Fig. 7 (a): since a low-Reynolds form of the turbulence model is used, the laminar solution is realized and the computed results overlap those obtained under the laminar condensate flow assumption.

The key observation with the laminar condensate flow assumption in Fig. 7 (a) is the minor effect of mass flux on the heat transfer coefficient only at high vapour qualities ( $x>0.8)$, with the results at lower vapour qualities being independent of mass flux and vapour quality. This trend is, in general, not consistent with experimental data $[6,8,9,18,19]$ over the full range of mass fluxes considered. However it is very interesting to notice in Fig. 2 that experimental data at $G=200 \mathrm{~kg} \mathrm{~m}^{-2} \mathrm{~s}^{-1}$ and $G=100 \mathrm{~kg} \mathrm{~m}^{-2} \mathrm{~s}^{-1}$ are very close and the two series overlap at $x<0.3$; besides, in the work by Matkovic et al. [6] the condensation of R32 in the same minichannel is shown to display exactly the same heat transfer coefficient values versus quality at $G=200 \mathrm{~kg}$ $\mathrm{m}^{-2} \mathrm{~s}^{-1}$ and $G=100 \mathrm{~kg} \mathrm{~m}^{-2} \mathrm{~s}^{-1}$; therefore some experimental evidence exists that for laminar condensate flow the heat transfer coefficient during condensation in circular minichannels is almost independent on mass flux.

A comparative analysis of the behavior at low and high mass flux is provided in Fig. 7 (b) where the cross-sectional images of the interface computed under the laminar liquid film assumption at $G=100 \mathrm{~kg} \mathrm{~m}^{-2} \mathrm{~s}^{-1}$ and $1000 \mathrm{~kg} \mathrm{~m}^{-2} \mathrm{~s}^{-1}$ are plotted; the laminar film approach is 
used beyond its range of validity at the high mass flux to explain the results in Fig. 7 (a). Both simulations predict some extent of stratification; with the exception of the results at very high vapour quality, the condensate film displays almost the same thickness at the top of the channel $(\approx 20 \mu \mathrm{m})$, while the thickness of the liquid at the bottom is lower at the higher mass flux. When stratification occurs, the contribution of the channel bottom to the global cross-sectional heat flux is negligible. This explains the very weak effect of mass flux on the heat transfer coefficient shown in Fig. 7.

It is clear from this analysis that the theoretical models based on the laminar liquid film assumption cannot be used to predict the performance of a minitubes condenser for the whole range of typical operating mass fluxes. As an example, the model of Nebuloni and Thome [15] is used only if the dimensionless condensate film thickness is lower than $\delta^{+}=50$. The model of Wand and Rose [12], instead, is used for R134a up to $1300 \mathrm{~kg} \mathrm{~m}^{-2} \mathrm{~s}^{-1}$ with tube diameters in the range $0.5-5 \mathrm{~mm}$.

\subsection{Influence of turbulence}

Unlike the laminar liquid film approach, the SST $k-\omega$ approach captures the influence of mass flux on the condensation heat transfer coefficient. As already shown in Fig. 7, at very low mass flux $\left(G=50 \mathrm{~kg} \mathrm{~m}^{-2} \mathrm{~s}^{-1}\right.$, maximum liquid Reynolds number $\mathrm{Re}_{\mathrm{L}}=161$ at $\left.x=0.48\right)$ the results from this latter approach almost overlap those from the laminar liquid film approach. Since a low-Re turbulence model is used, the SST $k-\omega$ approach would be expected to predict both the laminar and turbulent solutions. However, at $G=100 \mathrm{~kg} \mathrm{~m}^{-2} \mathrm{~s}^{-1}$ and $G=200 \mathrm{~kg} \mathrm{~m}^{-2} \mathrm{~s}^{-1}$ much higher heat transfer coefficients are predicted with the SST $k-\omega$ approach, and the experimental data of Matkovic et al. [6] are overpredicted by 35\% and 54\%, respectively. At these operating conditions the liquid Reynolds number in the simulations ranges between $\operatorname{Re}_{\mathrm{L}}=0$ and $\operatorname{Re}_{\mathrm{L}}=$ 620; according to the estimation provided in Section 2.2 and the discussion in the previous section, the liquid film flow is expected to be transitional. It is also important to note that the velocity field, the velocity strain rate and the liquid film thickness vary both axially and circumferentially so that the transitional problem is fully three-dimensional. The reason for the heat transfer being overpredicted at $G=100 \mathrm{~kg} \mathrm{~m}^{-2} \mathrm{~s}^{-1}$ and $200 \mathrm{~kg} \mathrm{~m}^{-2} \mathrm{~s}^{-1}$ are as follows. First, as reported by Wilcox [33], most turbulence models are known to generally predict transition to turbulence at too low Reynolds numbers. Second, the choice of the turbulent Prandtl number in Eq. (8) is important. In the present numerical study the turbulent Prandtl number is set to $\operatorname{Pr}_{t}=$ 0.85 , which corresponds to the common practice for two-equations turbulence models.

However, a variety of values have been suggested in the literature. Kays [43] suggested that the turbulent Prandtl number is a function of the turbulent Peclet number $\operatorname{Pe}_{t}=\operatorname{Pr} \mu_{t} / \mu$ : at large values of $\mathrm{Pe}_{\mathrm{t}}$ the turbulent Prandtl number in the logarithmic region of the boundary layer is found to approach a constant value of about 0.85 , but at small values of $\mathrm{Pe}_{\mathrm{t}}$ (i.e., at limited turbulence levels) it is found to increase indefinitely. In a work by Abraham et al. [44] based on 
the turbulence transition model of Menter et al. [45], numerical simulations of single-phase heat transfer found that a Reynolds-dependent turbulent Prandtl number is needed. In particular, the value $\operatorname{Pr}_{t}=0.9$ is found to be suitable for laminar flow $(\operatorname{Re}<2300)$, while for transitional flows the turbulent Prandtl number needed to be increased in order to decrease the turbulent thermal conductivity (see Eq. (8)) and avoid overprediction of the heat transfer coefficient.

At mass fluxes higher than $G=400 \mathrm{~kg} \mathrm{~m}^{-2} \mathrm{~s}^{-1}$ the present numerical results with the SST $k-\omega$ approach display good agreement with experimental data. As seen in Fig. 6, the strain rate inside the liquid film boundary layer is very high at the high mass fluxes; under these conditions the turbulence production is also very high and the stress limiter feature of Menter [35] plays a very important role in the SST $k$ - $\omega$ model . To illustrate the importance of this term, a simulation was conducted at $G=800 \mathrm{~kg} \mathrm{~m}^{-2} \mathrm{~s}^{-1}$ using the standard $k$ - $\omega$ model formulation [33] without any stress limiter implemented. The comparison in Fig. 8 shows that the heat transfer coefficients computed with the latter model are roughly twice as large as the experimental data, while a very good agreement is achieved with the SST $k-\omega$ approach.

In Fig. 9 (a) the condensation processes at $G=100 \mathrm{~kg} \mathrm{~m}^{-2} \mathrm{~s}^{-1}$ and $1000 \mathrm{~kg} \mathrm{~m}^{-2} \mathrm{~s}^{-1}$ are compared in terms of liquid film thickness plotted as a function of the angular coordinate, moving from the channel top down to the bottom. In Fig. 9(b) the effective thermal conductivity inside the condensate film is plotted along the vertical axis. Once again it is shown that during stratified condensation at $G=100 \mathrm{~kg} \mathrm{~m}^{-2} \mathrm{~s}^{-1}$ the film thickness stays constant between $25 \mu \mathrm{m}$ and $15 \mu \mathrm{m}$ in the upper part of the channel and a minimum thickness (due to the effect of surface tension) is achieved at approximately half the channel height. The key observation in Fig. 9, however, is the fact that the average condensate thickness is higher at $G=1000 \mathrm{~kg} \mathrm{~m}^{-2} \mathrm{~s}^{-1}$ as compared to $G$ $=100 \mathrm{~kg} \mathrm{~m}^{-2} \mathrm{~s}^{-1}$. In fact, during turbulent condensate flow, the heat flux (at fixed saturation-towall temperature difference) is no longer dependent mainly on the film thickness; instead the resulting thermal resistance is more affected by the turbulent thermal conductivity. As shown in Fig. 9, under laminar flow the effective conductivity is equal to the molecular conductivity $\lambda_{\text {eff }}=$ $\lambda=0.076 \mathrm{~W} \mathrm{~m}^{-1} \mathrm{~K}^{-1}$, while values up to 30 times higher are achieved at $G=1000 \mathrm{~kg} \mathrm{~m}^{-2} \mathrm{~s}^{-1}$ inside the condensate film because of turbulence: this result explains why much higher condensation heat transfer coefficients are achieved in the latter case even if the film is not thinner.

As a final analysis of R134a condensation inside minichannels under turbulent conditions, the non-dimensional condensate film thickness $\delta^{+}=\delta\left(\tau_{w} \rho_{L}\right)^{1 / 2} \mu_{L}^{-1}$ is plotted against the liquid Reynolds number $\operatorname{Re}_{\mathrm{L}}=(1-x) G D / \mu_{\mathrm{L}}$. The results are shown in Fig. 10 and the following correlation by Kosky [46] is also included for comparison:

$$
\delta^{+}=\left(\operatorname{Re}_{L} / 2\right)^{1 / 2} \quad \text { for } \delta^{+}<25
$$




$$
\delta^{+}=0.0504 \operatorname{Re}_{L}^{7 / 8} \quad \text { for } \delta^{+}>25
$$

The computed film thickness $\delta$ and the wall shear stress $\tau_{w}$ are obtained as cross-sectional averages from the numerical simulations and the liquid density and viscosity are evaluated at the wall temperature. The Kosky [46] correlation is not valid for stratified flows, therefore the series at $G=100 \mathrm{~kg} \mathrm{~m}^{-2} \mathrm{~s}^{-1}$ and $G=200 \mathrm{~kg} \mathrm{~m}^{-2} \mathrm{~s}^{-1}$, which are provided in Fig. 10 for comparison, cannot be compared against this correlation. Good agreement is seen between the simulations at high mass fluxes and the correlation; however the change in the slope of the non-dimensional thickness versus Reynolds number curve, which is expected to occur at $\operatorname{Re}_{\mathrm{L}} \sim 1000$ or $\delta^{+}=25$, is predicted by the simulations to occur at lower Reynolds numbers.

\section{CONCLUSIONS}

Three-dimensional numerical simulations of condensation of R134a are presented. Mass fluxes ranging from $G=50 \mathrm{~kg} \mathrm{~m}^{-2} \mathrm{~s}^{-1}$ up to $G=1000 \mathrm{~kg} \mathrm{~m}^{-2} \mathrm{~s}^{-1}$ are considered in a circular minichannel of $1 \mathrm{~mm}$ inner diameter. The Volume of Fluid method is used to track the vapourliquid interface, with the effects of interfacial shear stress, gravity and surface tension taken into account. The minichannel wall is held isothermal at a uniform temperature of $30^{\circ} \mathrm{C}$, while the refrigerant saturation temperature is $40{ }^{\circ} \mathrm{C}$. The inlet quality is $x=1$ and the refrigerant is condensed till a vapour quality of $x=0.5$ is reached. The problem is treated as being at steady state, since experimental visualization studies available in the literature reveal that the flow pattern is expected to be annular in this case without the presence of waves.

1. The influence of turbulence in the condensate film is analysed and compared against the assumption of laminar condensate flow by adopting two different computational approaches. The approach referred to as laminar liquid film corresponds to the assumption that the flow is laminar inside the liquid phase: turbulence is handled by a modified $k-\omega$ model [34] which retains the standard low-Reynolds formulation of the turbulent viscosity inside the vapour phase and sets it to be null inside the liquid film. The approach referred to as SST $k$ - $\omega$ adopts the low-Reynolds SST $k$ - $\omega$ model [35] through the whole computational domain.

2. Computational results are validated against experimental data of Matkovic et al. [6] obtained in a $0.96 \mathrm{~mm}$ i.d. circular minichannel. With the laminar liquid film approach used at mass fluxes between $100 \mathrm{~kg} \mathrm{~m}^{-2} \mathrm{~s}^{-1}$ and $200 \mathrm{~kg} \mathrm{~m}^{-2} \mathrm{~s}^{-1}$ (i.e., all-liquid Reynolds number $\left.619 \leq \operatorname{Re}_{\mathrm{LO}} \leq 1239\right)$ and the SST $k-\omega$ approach used at mass fluxes between 400 $\mathrm{kg} \mathrm{m}^{-2} \mathrm{~s}^{-1}$ and $1000 \mathrm{~kg} \mathrm{~m}^{-2} \mathrm{~s}^{-1}$ (i.e., $2478 \leq \mathrm{Re}_{\mathrm{LO}} \leq 6194$ ), the experimental data are predicted to within $4 \%$ average deviation and $14 \%$ standard deviation. 
3. Results obtained with the laminar liquid film approach are shown to agree well with the theoretical predictions of Wang and Rose [11] (which also assumes a laminar liquid film). Under the assumption of laminar condensate flow, experimental data at low mass fluxes $\left(G=100 \mathrm{~kg} \mathrm{~m}^{-2} \mathrm{~s}^{-1}\right.$ and $G=200 \mathrm{~kg} \mathrm{~m}^{-2} \mathrm{~s}^{-1}$ ) are satisfactorily predicted, but almost no effect of the mass flux on the condensation heat transfer coefficient is indicated. Such a result is, in general, not consistent with experimental data available in the literature $[6,8,9,18,19]$.

4. The influence of mass flux on the condensation heat transfer coefficient as obtained in experimental measurements can be predicted only if the assumption of laminar condensate flow is relaxed and turbulence in the film is taken into account. Since a lowReynolds number turbulence model is used, the SST $k$ - $\omega$ approach should predict both turbulent and laminar flow. However an earlier transition to turbulent flow in the condensate is found in the simulations relative to the experiments: at $G=50 \mathrm{~kg} \mathrm{~m}^{-2} \mathrm{~s}^{-1}$ the same results as the laminar liquid film are obtained; at $G=100 \mathrm{~kg} \mathrm{~m}^{-2} \mathrm{~s}^{-1}$ and 200 $\mathrm{kg} \mathrm{m}^{-2} \mathrm{~s}^{-1}$, the experiments are overpredicted by $35 \%$ and $54 \%$; and at mass fluxes above $400 \mathrm{~kg} \mathrm{~m}^{-2} \mathrm{~s}^{-1}$, good agreement with experimental data is achieved.

5. At low mass fluxes the R134a condensation process in a $1 \mathrm{~mm}$ i.d. minichannel is found to be gravity-dominated with laminar condensate flow. The liquid condensed in the upper part of the tube is drained to the bottom by gravity, while in the upper half of the tube the film thickness remains uniform irrespective of vapour quality or mass flux. The very weak influence of mass flux on heat transfer coefficient is attributed to the turbulent thermal conductivity being null and the contribution of the channel bottom to the global cross-sectional heat flux being negligible under stratified conditions.

6. At high mass fluxes the turbulent condensate flow is found to be almost perfectly annular: the condensate thickness is axisymmetrical and increases along the channel length. Even if the condensate thickness can be higher than at low mass fluxes, much higher heat transfer coefficients are achieved since the turbulent conductivity is dominant over the laminar value.

\section{ACKNOWLEDGEMENTS}

Prof. J.W. Rose and Dr. H.S. Wang, Queen Mary University of London, are acknowledged for the computational results provided for comparison.

\section{REFERENCES}

[1] D. Del Col, A. Cavallini, E. Da Riva, S. Mancin, G. Censi, Shell-and-tube minichannel condenser for low refrigerant charge, Heat Transfer Engineering 31(6) (2010) 509-517. 
[2] A. Cavallini, E. Da Riva, D. Del Col, Performance of a large capacity propane heat pump with low charge heat exchangers, International Journal of Refrigeration 33 (2010) 242250 .

[3] E. Da Riva, Two-phase heat transfer in minichannel heat exchangers: heat pump applications, design, modelling, PhD Thesis, University of Padova, Italy, 2009, available from: http://paduaresearch.cab.unipd.it/1784/

[4] S. Garimella, Condensation in minichannels and microchannels, in: S.G Kandlikar, S. Garimella, D. Li, S. Colin, M.R. King, Heat Transfer and Fluid Flow in Minichannels and Microchannels, Elsevier Ltd., Oxford, UK, 2006.

[5] A. Cavallini, L. Doretti, M. Matkovic, L. Rossetto, Update on condensation heat transfer and pressure drop in minichannels, Heat Transfer Engineering 27 (4) (2006) 74-87.

[6] M. Matkovic, A. Cavallini, D. Del Col, L. Rossetto, Experimental study on condensation heat transfer inside a single circular minichannel, IJHMT 52 (2009) 2311-2323.

[7] A. Cavallini, S. Bortolin, D. Del Col, M. Matkovic, L. Rossetto, Condensation Heat Transfer and Pressure Losses of High- and Low-Pressure Refrigerants Flowing in a Single Circular Minichannel, Heat Transfer Engineering, 32 (2) (2011) 1-9.

[8] T.M. Bandhauer, A. Agarwal, S. Garimella, Measurement and modeling of condensation heat transfer coefficients in circular microchannels, Trans. ASME Journal of Heat Transfer 128 (10) (2006) 1050-1059.

[9] S. Koyama, K. Kuwahara, K. Nakashita, K. Yamamoto, An experimental study on condensation of refrigerant R134a in a multi-port extruded tube, International Journal of Refrigeration 24 (2003) 425-432.

[10] A. Cavallini, D. Del Col, L. Doretti, M. Matkovic, L. Rossetto, C. Zilio, Condensation in horizontal smooth tubes: a new heat transfer model for heat exchanger design, Heat Transfer Engineering 27 (8) (2006) 31-38.

[11] H.S. Wang, J.W. Rose, A theory of film condensation in horizontal non-circular section microchannels, Trans. ASME Journal of Heat Transfer 127 (10) (2005) 1096-1105.

[12] H.S. Wang, J.W. Rose, Film condensation in horizontal circular-section microchannels, International Journal of Engineering Systems Modelling and Simulation 1 (2009) 115121.

[13] S.W. Churchill, Friction-factor equation spans all fluid-flow regimes, Chemical Engineering 84 (1977) 91-92.

[14] H.S. Mickley, R.C. Ross, A.L. Squyers, W.E. Stewart, Heat, mass and momentum transfer for flow over a flat plate with blowing or suction, Rep. No. NACA-TN-3208 (1954).

[15] S. Nebuloni, J.R. Thome, Numerical modeling of laminar annular film condensation for different channel shapes, IJHMT 53 (2010) 2615-2627. 
[16] Y.Y. Yan, T. Lin, Condensation heat transfer and pressure drop of refrigerant R-134a in a small pipe, IJHMT 42 (1999) 697-708.

[17] P.K. Panday, Two-dimensional turbulent film condensation of vapours flowing inside a vertical tube and between parallel plates: a numerical approach, International Journal of Refrigeration 26 (2003) 492-503.

[18] D. Del Col, S. Bortolin, A. Cavallini, M. Matkovic, Effect of cross sectional shape during condensation in a single square minichannel, IJHMT 54 (17-18) (2011) 3909-3920.

[19] X. Quan, L. Dong, P. Cheng, Determination of annular condensation heat transfer coefficient of steam in microchannels with trapezoidal cross sections, IJHMT 53 (19-20) (2010) 3670-3676.

[20] E. Da Riva, J.M. Corberán, E.L. Cuadros, Longitudinal heat conduction study of a uniform power density apparatus for the experimental determination of the heat transfer coefficient, International Journal of Thermal Sciences 48 (2009) 1138-1150.

[21] J.W. Coleman, S. Garimella, Two-phase flow regime transitions in microchannel tubes: the effect of hydraulic diameter, ASME HTD 366-4 (2000) 71-83.

[22] S. Garimella, J.D. Killion, J.W. Colemann, An experimentally validated model for twophase pressure drop in the intermittent flow regime for circular microchannels, ASME Journal of Fluids Engineering 124 (2002) 205-214.

[23] C.W. Hirt, B.D. Nichols, Volume of fluid (VOF) method for the dynamics of free boundaries, J. Comput. Phys. 39 (1981) 201-225.

[24] ANSYS Fluent 13 Theory Guide, ANSYS Inc., Canonsburg PA, USA (2010).

[25] S. Muzaferija, M. Peric, P. Sames, T. Schellin, T., A two-fluid Navier-Stokes solver to simulate water entry, in: Proc. $22^{\text {nd }}$ Symposium on Naval Hydrodynamics, Washington DC, 1998, 277-289.

[26] T. Boeck, J. Li, E. López-Pagés, P. Yecko, S. Zaleski, Ligament formation in sheared liquid-gas layers, Theoretical and Computational Fluid Dynamics 21 (2007) 59-76.

[27] NIST, 2007, National Institute of Standard and Technology, Refprop8, Boulder Colorado.

[28] J.U. Brackbill, D.B. Kothe, C. Zemach, 1992, A continuum method for modeling surface tension, J. Comput. Phys. 100 (1992) 335-354.

[29] A. Cavallini, Brown J.S, Del Col D., Zilio C., In-tube condensation performance of refrigerants considering penalization terms (exergy losses) for heat transfer and pressure drop. Int. Journal of Heat and Mass Transfer, vol. 53 (2010) 2885-2896.

[30] D.P. Traviss, W.M. Rohsenow, A.B. Baron, Forced-convection condensation inside tubes: a heat transfer equation for condenser design, ASHRAE Transac. 79 (1973) 157165.

[31] A. Cavallini, G. Censi, D. Del Col, L. Doretti, G.A. Longo, L. Rossetto, Experimental investigation on condensation heat transfer and pressure drop of new HFC refrigerants 
(R134a, R125, R32, R410A, R236ea) in a horizontal smooth tube, International Journal of Refrigeration 24 (2001) 73-87.

[32] F.G. Carpenter, A.P. Colburn, The effect of vapor velocity on condensation inside tubes, General Discussion of Heat Transfer, The Institute of Mechanical Engineers and ASME, 1951, pp. 20-26.

[33] D.C. Wilcox, Turbulence Modeling for CFD, second ed., DCW Industries, Inc., La Cañada, California, USA, 1998.a

[34] E. Da Riva, D. Del Col, Numerical simulation of laminar liquid film condensation in a horizontal circular minichannel, ASME Journal of Heat Transfer, 2012 (IN PRESS) [DOI: 10.1115/1.4005710].

[35] F.R. Menter, Two-equation eddy-viscosity turbulence models for engineering applications, AIAA Journal 32 (1994) 1598-1605.

[36] P. Bradshaw, D.H. Ferriss, N.P. Atwell, Calculation of boundary layer development using the turbulent energy equation, Journal of Fluid Mechanics 28 (1967) 593-616.

[37] D.C. Wilcox, Formulation of the k- $\omega$ turbulence model revisited, AIAA J. 46 (11) (2008) 2823-2838. Y.

[38] Y. Egorov, Validation of CFD codes with PTS-relevant test cases, Contact condensation in stratified steam-water flow, EVOL-ECORA-D 07 (2004).

[39] W. H. Lee, 1980, A pressure iteration scheme for two-phase flow modeling, in: T.N. Veziroglu (Ed.), Multiphase Transport Fundamentals, Reactor Safety, Applications, vol. 1, Hemisphere Publishing, Washington DC.

[40] E. Da Riva, D. Del Col, A. Cavallini, Modelling of condensation in a circular minichannel by means of the VOF method, Proc. International Heat Transfer Conference, August 8-13, 2010, Washington, DC, USA.

[41] E. Da Riva, D. Del Col, Effect of gravity during condensation of R134a in a circular minichannel, Microgravity Science and Technology 23 (suppl. 1) (2011) 87-97.

[42] H.S. Wang, J.W. Rose, Private communication, 2010.

[43] W. Kays, Turbulent Prandtl number - where are we?, J. Heat Transfer 116 (1994) 284295.

[44] J.P. Abraham, E.M. Sparrow, J.C.K. Tong, Heat transfer in all pipe flow regimes: laminar, transitional/intermittent, and turbulent, IJHMT 52 (2009) 557-563.

[45] F. Menter, R. Langtry, S. Likki, Y. Suzen, P. Huang, S. Volker, A correlation-based transition model using local variables - part I: model formulation, ASME Journal of Turbomachinery 128 (2006) 413-422.

[46] P. G. Kosky, Thin liquid films under simultaneous shear and gravity forces, IJHMT 14 (8) (1971) 1220-1224. 
Table 1: Cases considered in the simulations.

\begin{tabular}{llllll}
\hline $\begin{array}{l}G \\
{\left[\mathrm{~kg} \mathrm{~m}^{-2} \mathrm{~s}^{-1}\right]}\end{array}$ & $\begin{array}{l}\mathrm{Re}_{\mathrm{GO}} \\
{[-]}\end{array}$ & $\begin{array}{l}\mathrm{Re}_{\mathrm{LO}} \\
{[-]}\end{array}$ & $\begin{array}{l}\text { Turbulence } \\
\text { approach }\end{array}$ & $\begin{array}{l}\text { Length } \\
{[\mathrm{mm}]}\end{array}$ & $\begin{array}{l}\text { Outlet Quality } \\
{[-]}\end{array}$ \\
\hline 50 & 4041 & 310 & laminar liquid film & 38 & 0.48 \\
100 & 8082 & 619 & laminar liquid film & 75 & 0.44 \\
200 & 16164 & 1239 & laminar liquid film & 120 & 0.50 \\
400 & 32328 & 2478 & laminar liquid film & 230 & 0.51 \\
1000 & 80821 & 6194 & laminar liquid film & 600 & 0.47 \\
50 & 4041 & 310 & SST $k-\omega$ & 38 & 0.40 \\
100 & 8082 & 619 & SST $k-\omega$ & 60 & 0.38 \\
200 & 16164 & 1239 & SST $k-\omega$ & 100 & 0.29 \\
400 & 32328 & 2478 & SST $k-\omega$ & 130 & 0.35 \\
600 & 48493 & 3716 & SST $k-\omega$ & 140 & 0.39 \\
800 & 64657 & 4955 & SST $k-\omega$ & 150 & 0.41 \\
1000 & 80821 & 6194 & SST $k-\omega$ & 175 & 0.38 \\
\hline
\end{tabular}


Table 2: Comparison between experimental and calculated cross sectional average heat transfers coefficients.

\begin{tabular}{llll}
\hline$G$ & Condensate film & $e_{R}$ & $\sigma_{N}$ \\
{$\left[\mathrm{~kg} \mathrm{~m}^{-2} \mathrm{~s}^{-1}\right]$} & approach & {$[\%]$} & {$[\%]$} \\
\hline 100 & laminar & -10 & 4 \\
200 & laminar & -28 & 3 \\
400 & laminar & -56 & 2 \\
1000 & laminar & -76 & 5 \\
100 & SST $k-\omega$ & 35 & 4 \\
200 & SST $k-\omega$ & 54 & 12 \\
400 & SST $k-\omega$ & 22 & 7 \\
600 & SST $k-\omega$ & 14 & 5 \\
800 & SST $k-\omega$ & 5 & 6 \\
1000 & SST $k-\omega$ & 0 & 7 \\
\hline
\end{tabular}




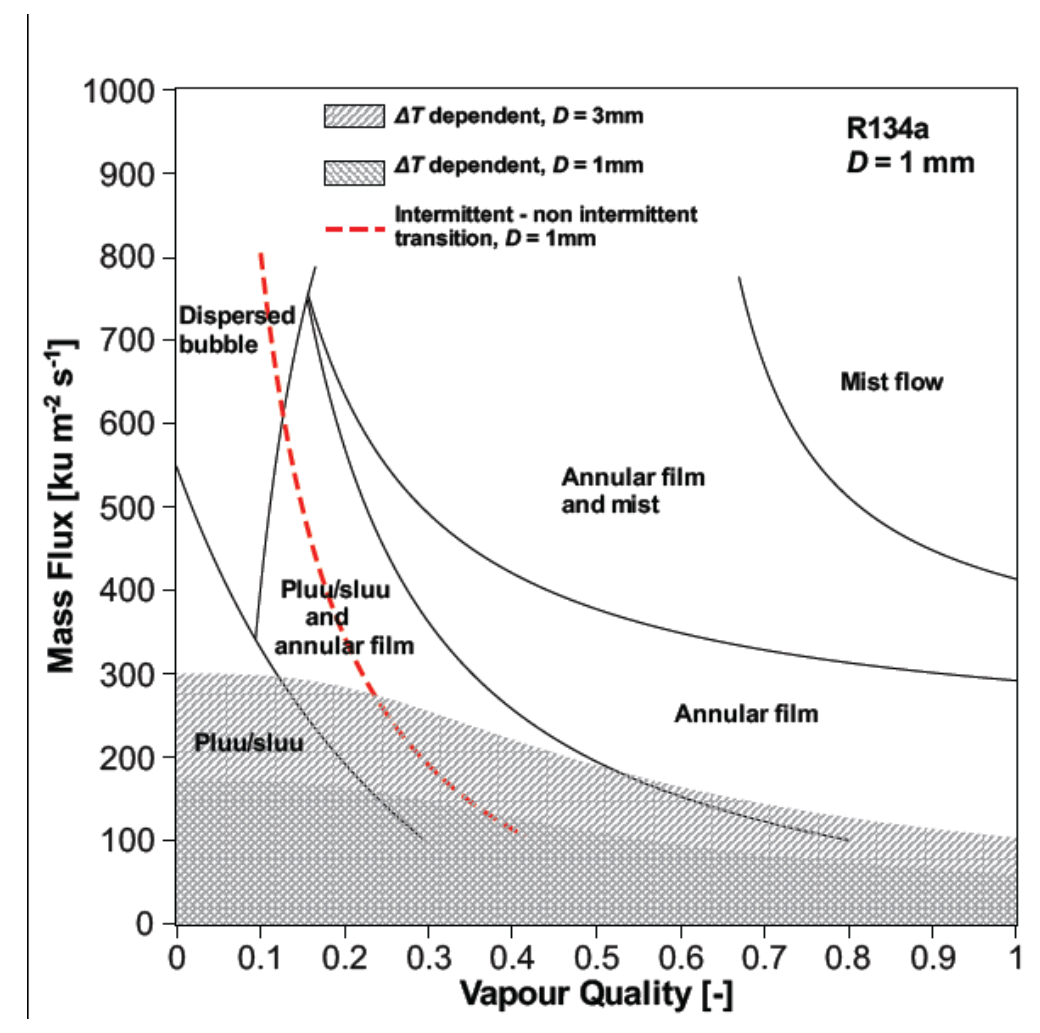

Fig. 1. Flow regime map by Coleman and Garimella [21] and Garimella [4] for R134a. Intermittent-non intermittent transition by Garimella et al. [22] and $\Delta \mathrm{T}$ dependent region by Cavallini et al. [10] are also depicted. 


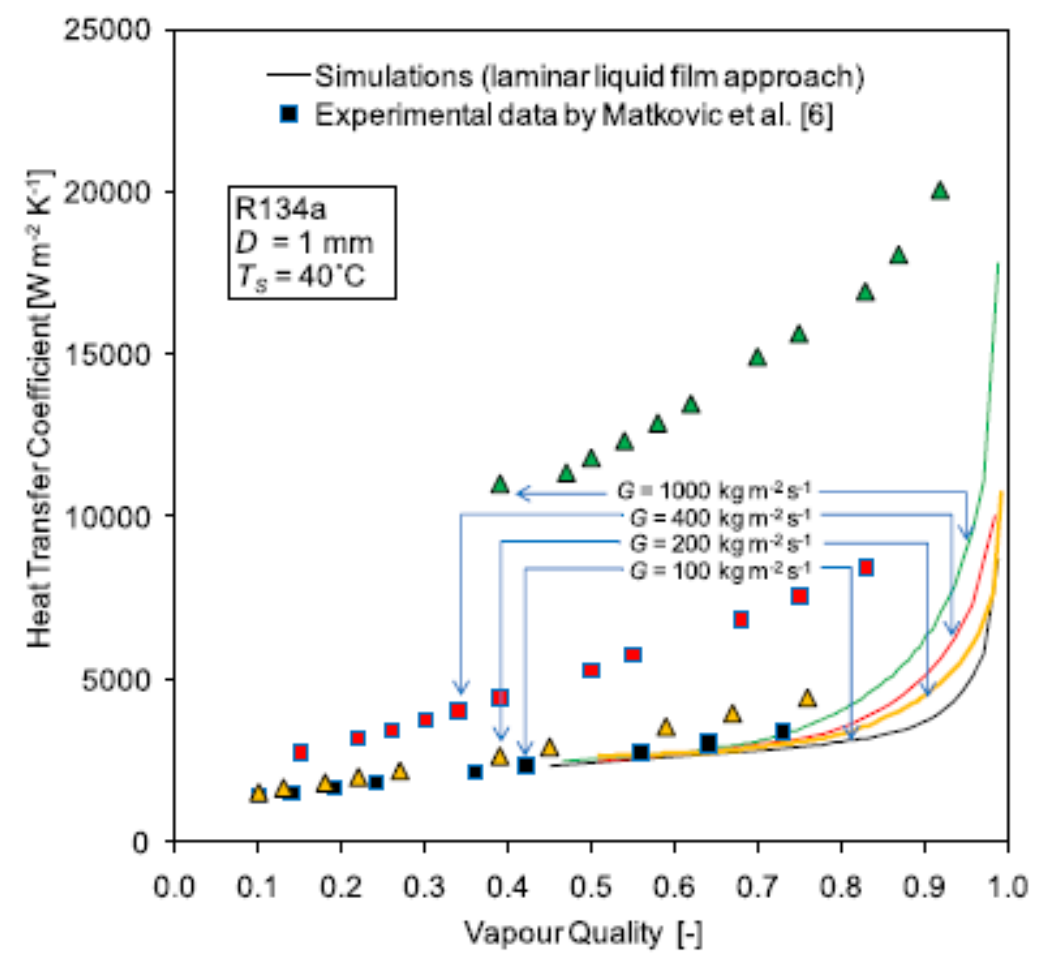

Fig. 2. Cross-sectional average heat transfer coefficient as a function of vapour quality.

Simulations with the laminar liquid film approach and experimental data from Matkovic et al. [6]. 


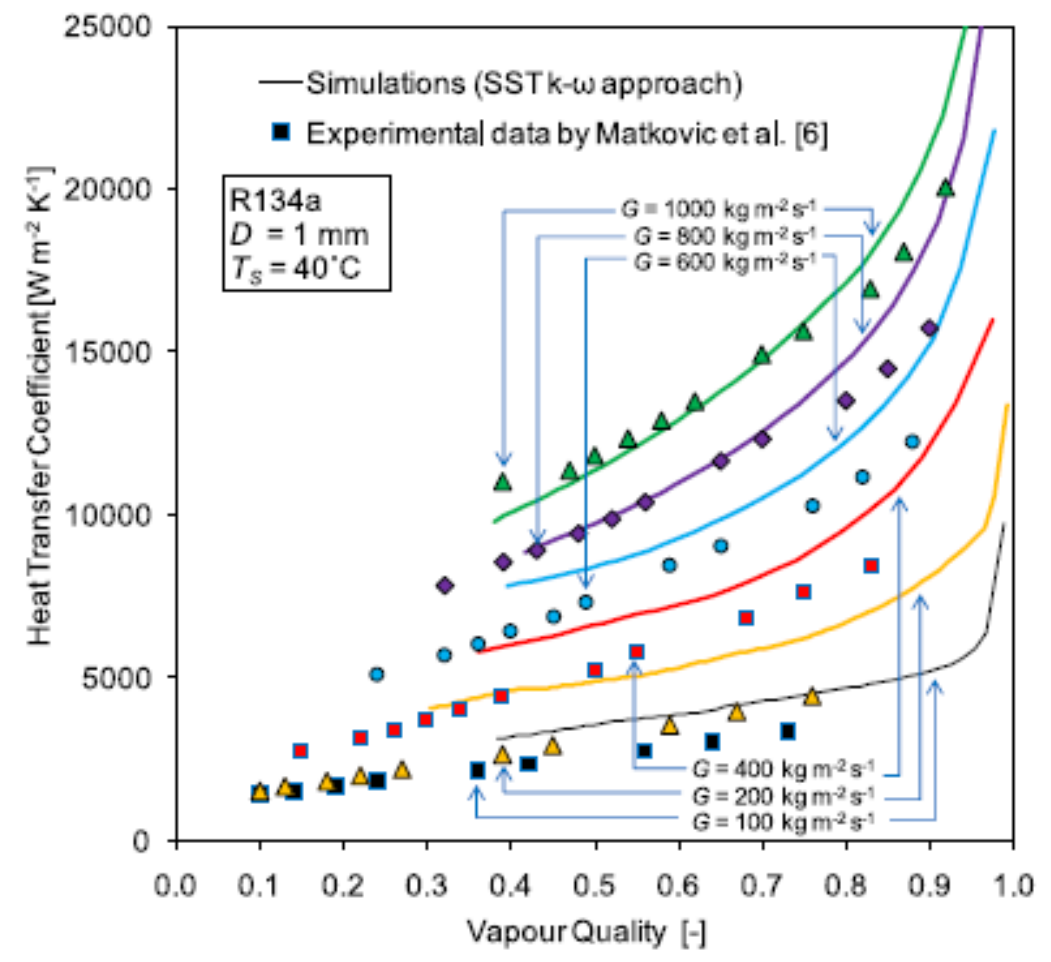

Fig. 3. Cross-sectional average heat transfer coefficient as a function of vapour quality. Simulations with SST k- $\omega$ approach and experimental data from Matkovic et al. [6]. 


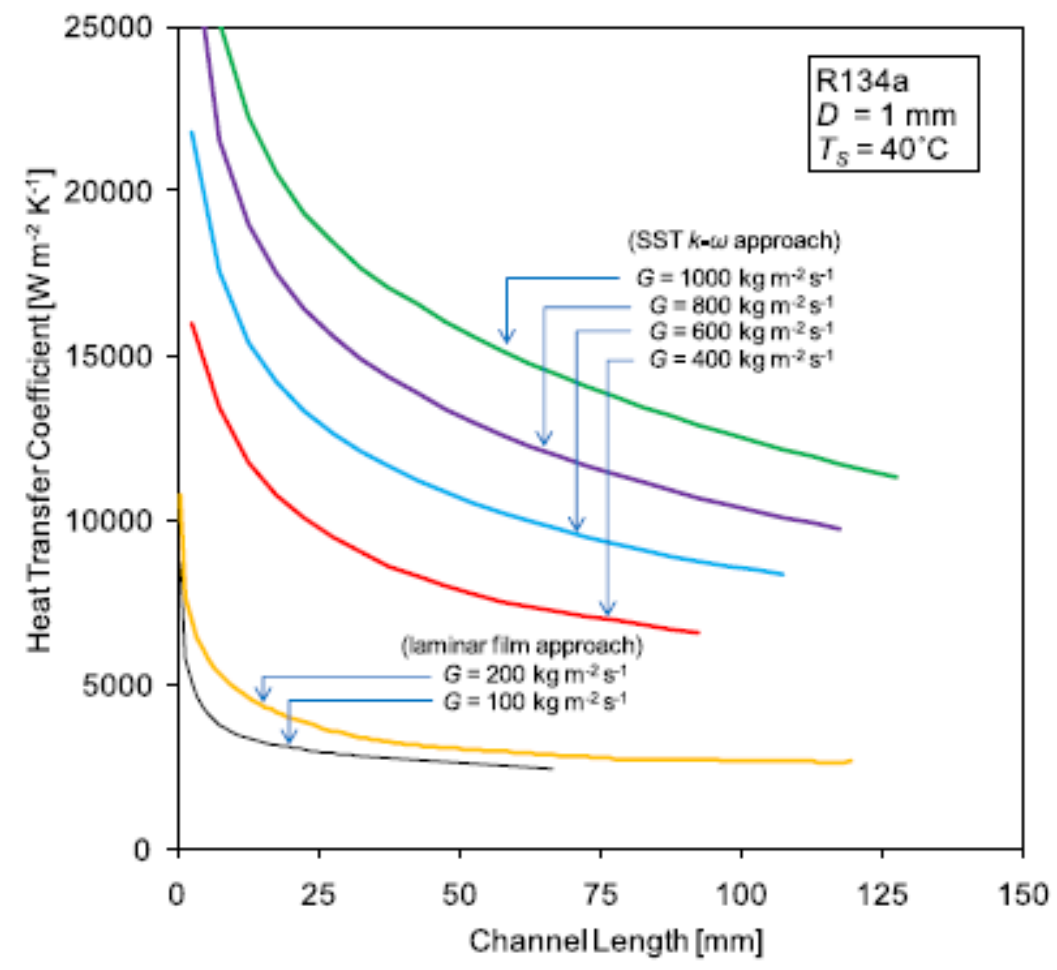

Fig. 4. Cross-sectional average heat transfer coefficient as a function of axial position. Each curve ends at $\mathrm{x}=0.5$. 


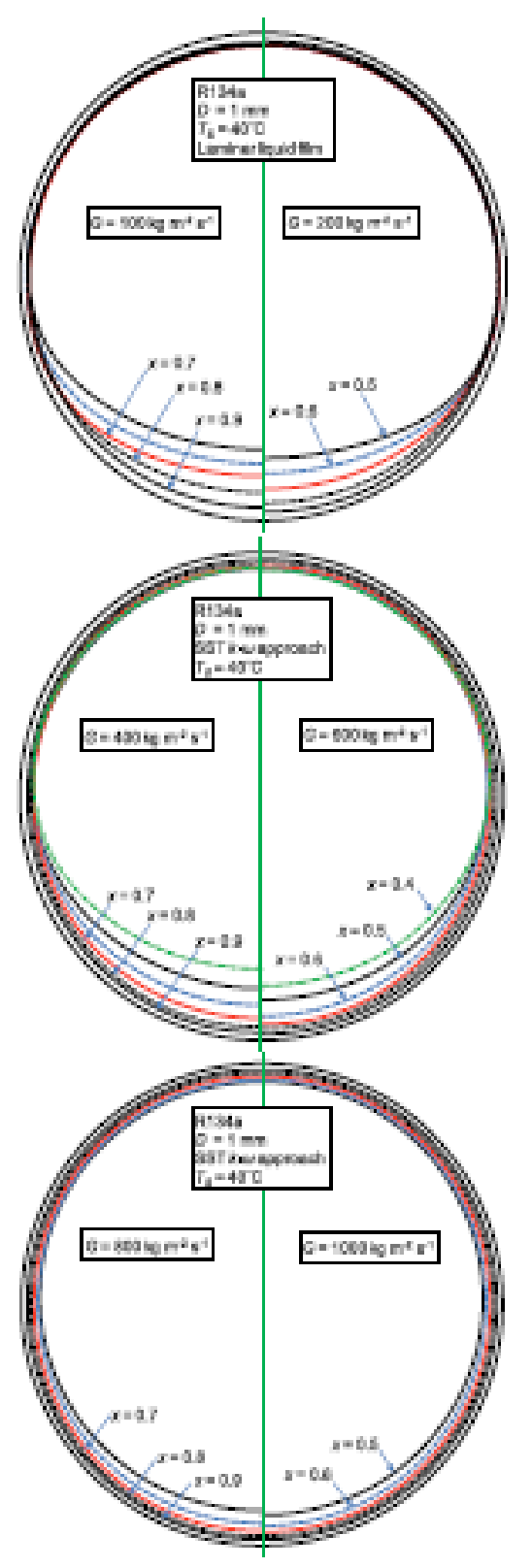

Fig. 5. Interface in minichannel cross section at different vapour qualities at $\mathrm{G}=100 \mathrm{~kg} \mathrm{~m}-2 \mathrm{~s}-1$, $\mathrm{G}=200 \mathrm{~kg} \mathrm{~m}-2 \mathrm{~s}-1, \mathrm{G}=400 \mathrm{~kg} \mathrm{~m}-2 \mathrm{~s}-1, \mathrm{G}=600 \mathrm{~kg} \mathrm{~m}-2 \mathrm{~s}-1, \mathrm{G}=800 \mathrm{~kg} \mathrm{~m}-2 \mathrm{~s}-1$ and $\mathrm{G}=1000$ $\mathrm{kg} \mathrm{m}-2 \mathrm{~s}-1$. 

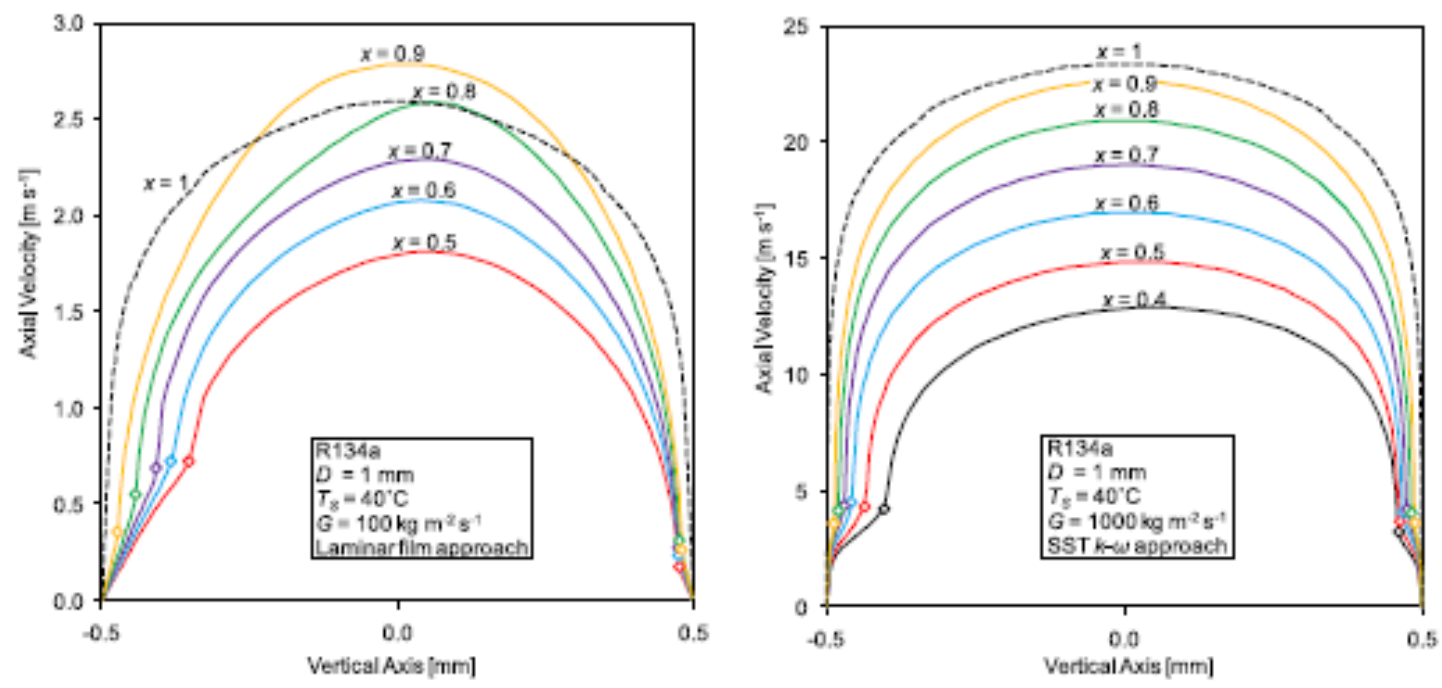

Fig. 6. Axial velocity along vertical axis at $\mathrm{G}=100 \mathrm{~kg} \mathrm{~m}-2 \mathrm{~s}-1$ and $\mathrm{G}=1000 \mathrm{~kg} \mathrm{~m}-2 \mathrm{~s}-1$ and different vapour qualities. 

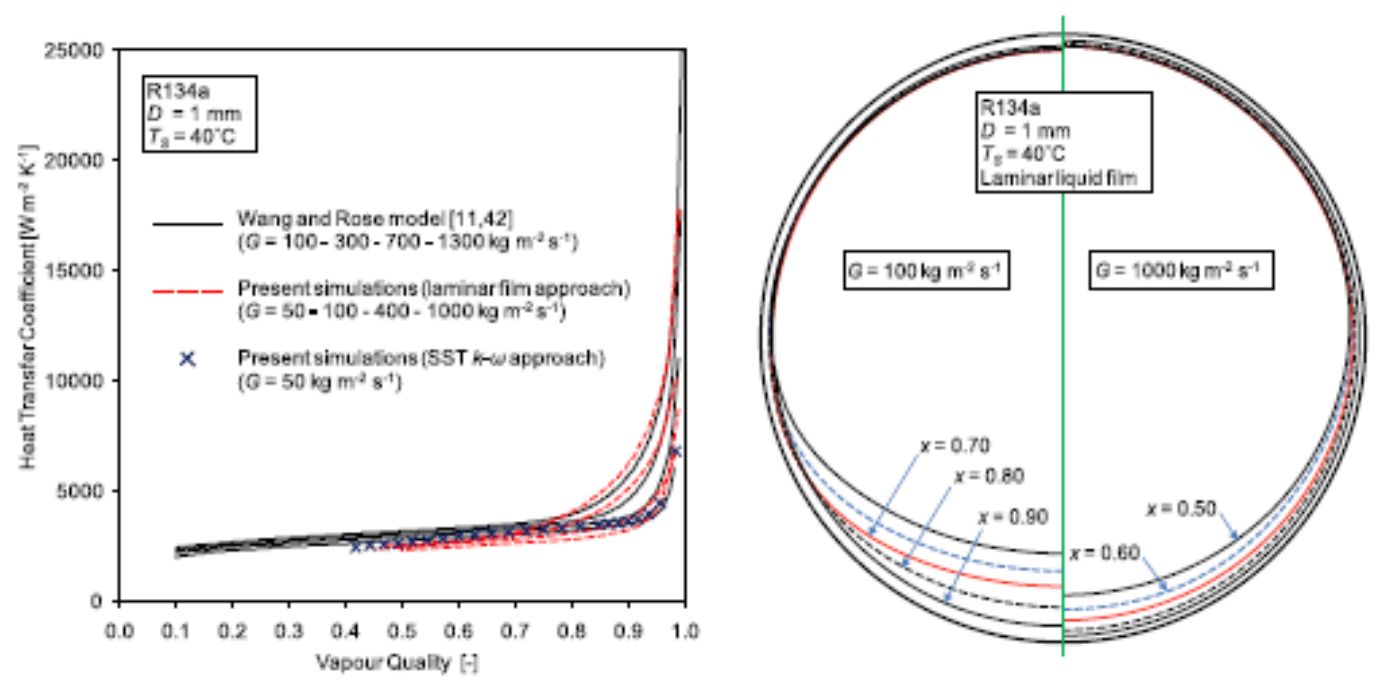

Fig. 7. (a) Comparison between the present computational results under the assumption of laminar condensate flow and predictions with the Wang and Rose [11,42] model. Numerical results at $\mathrm{G}=50 \mathrm{~kg} \mathrm{~m}-2 \mathrm{~s}-1$ with the SST k- $\omega$ approach are also depicted. (b) Interface in the minichannel cross-section computed under the laminar liquid film assumption at $\mathrm{G}=100 \mathrm{~kg}$ $\mathrm{m}^{-2} \mathrm{~s}^{-1}$ and $1000 \mathrm{~kg} \mathrm{~m}^{-2} \mathrm{~s}^{-1}$. 


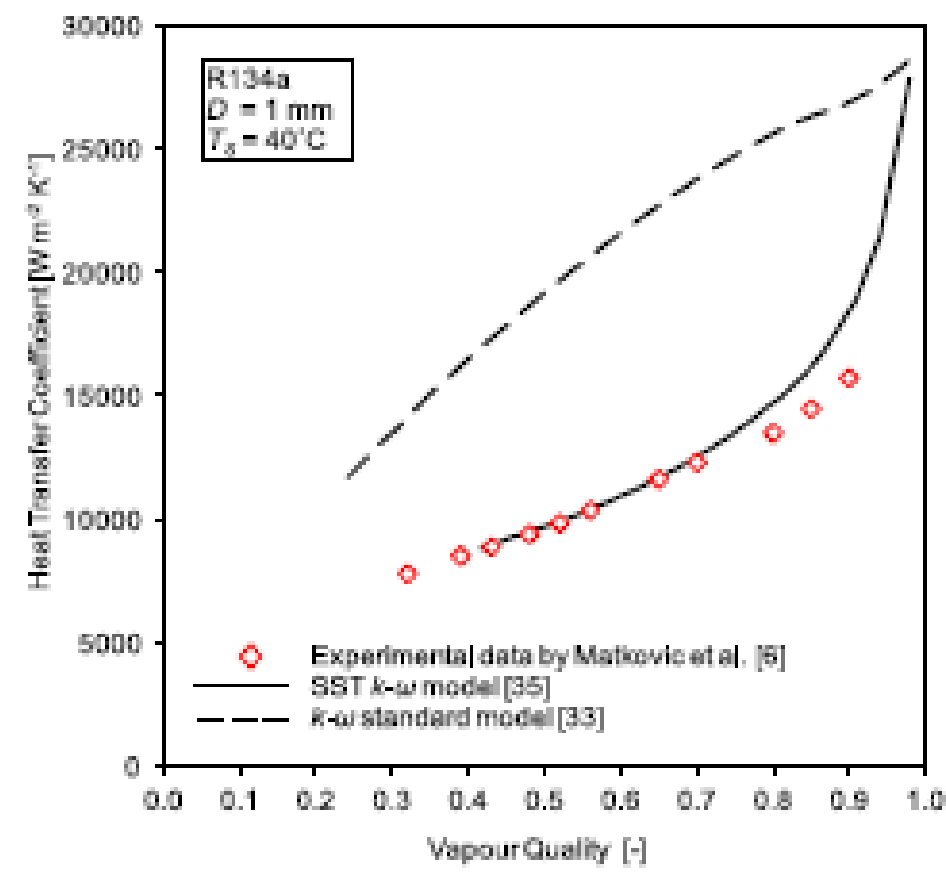

Fig. 8. Heat transfer coefficient as a function of vapour quality at $\mathrm{G}=800 \mathrm{~kg} \mathrm{~m}-2 \mathrm{~s}-1$ :

comparison between predictions with the SST k- $\omega$ model [35] and the standard k- $\omega$ model [33]. 

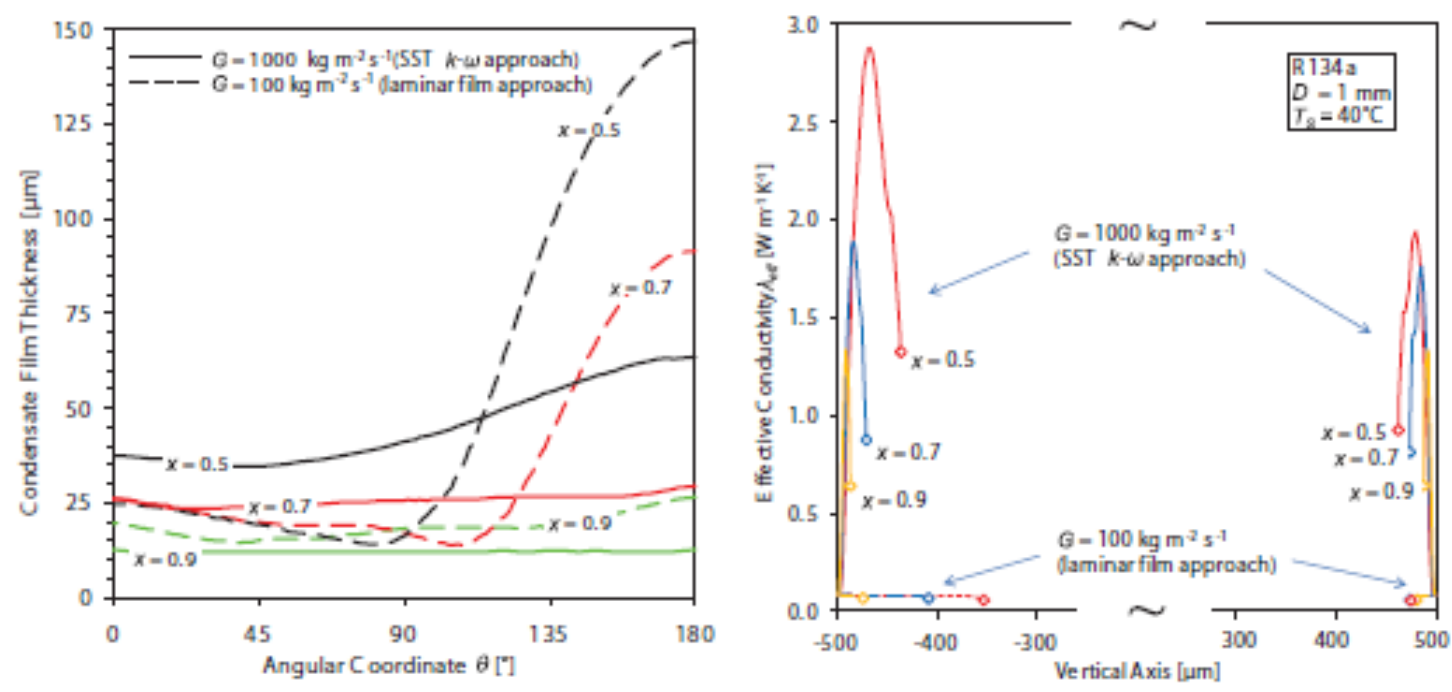

Fig. 9. (a) Condensate film thickness as a function of the angular coordinate from channel top at $\mathrm{G}=100 \mathrm{~kg} \mathrm{~m}-2 \mathrm{~s}-1$ and $1000 \mathrm{~kg} \mathrm{~m}-2 \mathrm{~s}-1$ and different vapour qualities. (b) Effective thermal conductivity along vertical axis at $\mathrm{G}=100 \mathrm{~kg} \mathrm{~m}-2 \mathrm{~s}-1$ and $1000 \mathrm{~kg} \mathrm{~m}-2 \mathrm{~s}-1$ and different vapour qualities. 


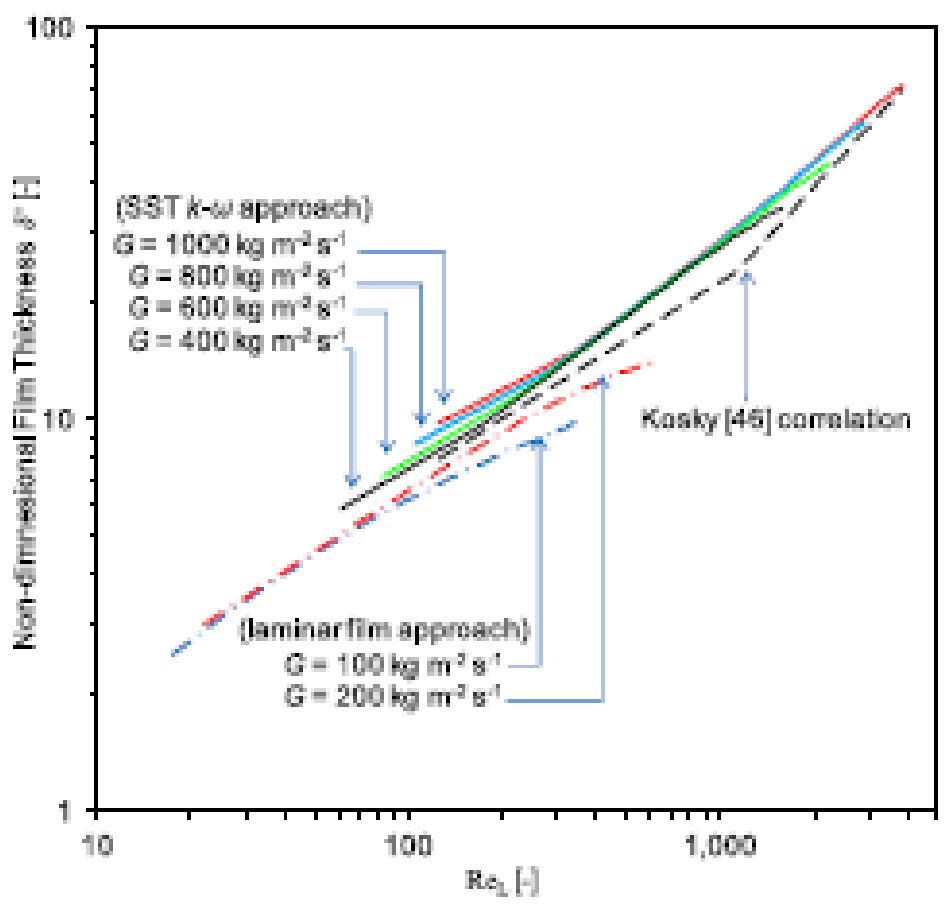

Fig. 10. Non-dimensional condensate film thickness versus liquid Reynolds number: comparison between present results and Kosky [46] correlation. 